\title{
Online reputation management by cancer hospitals: A systematic literature review in the USA and Spain
}

\author{
Pablo Medina-Aguerrebere; Toni González-Pacanowski; Eva Medina
}

How to cite this article:

Medina-Aguerrebere, Pablo; González-Pacanowski, Toni; Medina, Eva (2020). “Online reputation management by cancer hospitals: A systematic literature review in the USA and Spain". Profesional de la información, v. 29, n. 6, e290617.

https://doi.org/10.3145/epi.2020.nov.17

Manuscript received on $01^{\text {st }}$ April 2020 Accepted on $14^{\text {th }}$ September 2020

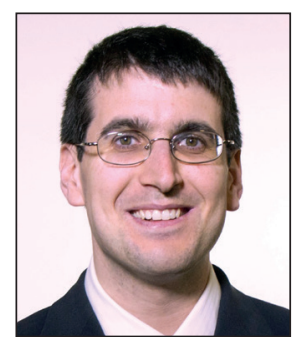

Pablo Medina-Aguerrebere https://orcid.org/0000-0002-4463-4721

Canadian University Dubai, Faculty of Communications, Arts and Sciences $1^{\text {st }}$ interchange, Sheikh Zayed Road Dubai, PO Box 117781

United Arab Emirates

pablo.medina@cud.ac.ae

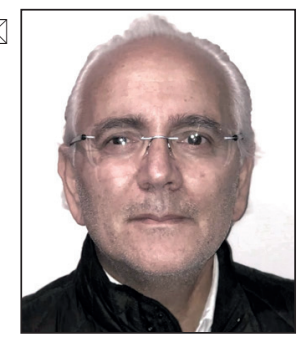

Toni González-Pacanowski https://orcid.org/0000-0003-3005-2218

University of Alicante

School of Communication and Psychology 03690 San Vicente Raspeig (Alicante), Spain toni.gonzalez@ua.es

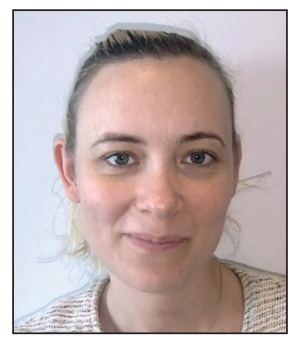

\author{
Eva Medina \\ https://orcid.org/0000-0001-6276-4127 \\ University of Alicante \\ School of Communication and Psychology \\ 03690 San Vicente Raspeig (Alicante), Spain \\ eva.medina25818@gmail.com
}

\begin{abstract}
Cancer hospitals manage social media platforms in a professional way to improve their relationships with internal and external stakeholders and reinforce their corporate brand. To do so, they need their health professionals to be involved: these professionals become brand ambassadors able to influence society. Nevertheless, they face different challenges: legal issues, new patients' demands, privacy-related matters, or the difficulty of disseminating scientific content. This literature review paper analyzes how cancer hospitals manage their social media platforms to improve their reputation. To do this, we carry out a systematic literature review focused on papers published in the USA and Spain, based on the Salsa framework proposed by Grant and Booth (2009). We then define an online corporate communication model allowing cancer hospitals to improve their reputation through Facebook, Twitter, and YouTube (MedPac Model for Building Cancer Hospital Brands). The paper concludes that this model is useful for cancer hospitals because it prioritizes persons (brand ambassadors) rather than companies, focuses on scientific and emotional content rather than business information, and is based on human values.
\end{abstract}

\section{Keywords}

Public health; Health organizations; Hospitals; Cancer; Corporate communication; Organizational communication; Public relations; Reputation; Branding; Stakeholders; Social media; Engagement; Review article.

This paper is a result of the "Interactive storytelling and digital visibility in the digital documentary and structured journalism" research project funded by Feder and the Spanish Ministry of Sciences, Innovation, and Universities (RTI2018-095714-B-C21). 


\section{Introduction}

Managing social media platforms in a professional way has become a true priority for healthcare organizations, especially cancer hospitals. In these organizations, patients need various sources of information as well as solid emotional support to enable them to face the disease and improve their empowerment. In this framework, social media platforms such as Facebook, Twitter, and YouTube play a key role as socialization agents with the ability to help patients participate in collective decision processes along with health professionals. On the other hand, thanks to these platforms, cancer hospitals can improve their brand reputation, build better relationships with stakeholders (patients, media companies, etc.), and boost their business. This paper aims to analyze how cancer hospitals should structure their social media platforms to improve their corporate reputation towards internal and external stakeholders. To do this, we carry out a systematic literature review about corporate communication, social media, reputation, and hospitals; thereafter, we propose a communication model for cancer hospitals.

According to Grant and Booth (2009), a systematic literature review must analyze the main concepts, trends, and ideas related to the chosen topic to advance an academic field; to do this, a systematic literature review can follow a simple analytical framework called Salsa (Search, AppraisaL, Synthesis, and Analysis), which is applied herein (see Table 1. Methodology).

- First, Search: We analyzed two databases: Scopus and Web of Science. In each, we used five different keywords (hospital, corporate communication, reputation, brand, and social media) in English and Spanish to identify papers related to this topic published between 2010 and 2020 in the main journals specialized in health communication, such as Journal of health communication or Corporate communications: An international journal.

- Second, Appraisal. After having identified more than 500 papers, we evaluated them and chose 146 in order to focus only on the main topic: cancer hospitals and their reputation through social media. To appraise these papers, we used the IMRaD structure as criteria, as well as their main parameters (keywords, title, methodology, and conclusion). From a geographical point of view, this research mainly focused on the USA and Spain, firstly because the journals with the highest reputation (impact factor) in the social sciences and health, as well as those specialized in health communication, are published in the USA, ${ }^{1}$ and secondly, because many Spanish universities have developed this domain by publishing scientific journals and proposing learning programs. $^{2}$

- Third, Synthesis. We read all the papers, especially their methodology, discussion, and conclusions, to identify the main concepts, trends, and approaches in this domain (see sections 2-6). And,

- Fourth, Analysis. We propose herein a communication model based on the literature review as well as our previous experience in order to advance this academic field (see section 7).

Table 1. Methodology

\begin{tabular}{|c|l|}
\hline Stage & \multicolumn{1}{|c|}{ Criteria } \\
\hline Search & $\begin{array}{l}\text { Databases } \\
\text { Scopus, Web of Science } \\
\text { Keywords } \\
\text { hospital, corporate communication, reputation, brand, social media } \\
\text { Languages } \\
\text { English, Spanish } \\
\text { Dates } \\
\text { 2010-2020 }\end{array}$ \\
\hline AppraisaL & $\begin{array}{l}\text { Number } \\
146 \text { papers chosen out of 500 papers } \\
\text { Criteria } \\
\text { IMRaD structure, main topics } \\
\text { Countries } \\
\text { USA and Spain }\end{array}$ \\
\hline Synthesis & $\begin{array}{l}\text { Focus } \\
\text { methodology, discussion, and conclusion } \\
\text { Key issues } \\
\text { concepts, trends, and approaches }\end{array}$ \\
\hline Analysis & $\begin{array}{l}\text { Proposal } \\
\text { MedPac Model for Building Cancer Hospital Brands }\end{array}$ \\
\hline
\end{tabular}

\section{Public health and communication}

Public health and communication are directly interrelated: health professionals need accurate information to deal efficiently with patients, while patients require different insights to improve understanding of their diseases and treatments (Hannawa et al., 2015). Even if there is a gap between public health theories and campaigns (Brent, 2016), both allow health professionals to build better relationships with their internal and external stakeholders -patients, public authorities, patients' associations, etc. (Jones et al., 2015). Experts in public health communication lead internal change to enhance the integration of this activity into the daily logic of all health professionals (Burleson, 2014).

According to Robinson et al. (2014), public health and communication directly influence the internal and external functioning of health organizations. When both domains work together, these organizations can implement a transdisciplinary approach based on the concerns of patients as well as the needs of health professionals (Nazione et al., 2013). In this context, health organizations become credible brands that can influence the perceptions of stakeholders about health-related issues such as prevention, education, or behaviors (Hendriks et al., 2014). These health brands play a key role, as patients require credible sources of in-

Health brands play a key role because patients need credible sources of medical information 
formation to improve their empowerment (Robinson et al., 2014). On the other hand, thanks to communication, health organizations can also better understand why stakeholders behave in a particular way (Burleson, 2014).

Several authors, such as Kwateng, Osei and EkowAbban (2014), have considered public health campaigns as an asset, as they allow patients to improve their health behaviors. Health professionals should be involved in these campaigns because communicating with patients before, during, and after their hospital visit can positively influence patient engagement (McKeever, 2014). All public health communication campaigns are based on efficient segmentation criteria, allowing these organizations to identify their main and secondary targets according to their behaviors and perceptions (Moran; Sussman, 2014). Thanks to such segmentation, these organizations can establish a bridge between their managerial needs and people's attitudes (Brent, 2016). According to Seo and Matsaganis (2013), people's attitudes are directly related to their educational and professional skills: in other words, people's background in terms of their family, school, university, and companies can determine their perceptions of public health campaigns. This background also influences their communicational behaviors: if patients receive a public health message about a topic in which they are expert, they are more likely to share this information with other patients (Hendriks et al., 2014). This is why, when health organizations launch anti-smoking campaigns, the knowledge and attitudes of patients about this domain directly determine their success (Jeong et al., 2015).

\section{Corporate communication by hospitals}

Hospitals can implement three different kinds of communication activities: interpersonal, internal, and external (Medina-Aguerrebere, 2018a). Managing all of these in a strategic way constitutes a priority for these organizations, because thanks to these initiatives, they can build relationships of trust with internal and external stakeholders (Rodrigues; Azevedo; Calvo, 2016).

\subsection{Interpersonal communication}

Many schools of medicine around the world have implemented various courses focused on interpersonal communication, to improve the interaction of health professionals with patients (Dean; Oetzel, 2014). Integrating interpersonal communication skills into the daily logic of health professionals constitutes a priority as well as an opportunity to improve patient care (Grajales et al., 2014). According to Paternotte et al. (2014), these courses should focus on four main areas: (a) language differences, (b) perceptions about diseases and treatments, (c) the social value of communication, and (d) clichés. If health professionals integrate these insights into their daily work, this could help health organizations become more efficient, thereby determining the perceptions of patients regarding the medical service (McKeever, 2014).

Experts in health communication explain to health professionals why interpersonal communication skills are so important to improve their efficiency as health providers (Medina-Aguerrebere, 2018a) and to enhance patient satisfaction as well as quality of care (Marca-Francés; Frigola-Reig; Compte-Pujol, 2019). The main reasons are that, thanks to interpersonal communication, health professionals can: (a) listen to patients before interacting with them (Jahromi et al., 2016), (b) integrate patient's attitudes, motivations, and intentions into their scientific speech about treatments and diseases (D'Agostino; Bylund, 2014), (c) adapt their behavior to different cultural elements, such as religion, language, or social beliefs (Weech-Maldonado et al., 2012), (d) manage positive and negative emotions when patients receive different news concerning their disease (De Vries et al., 2018), and (e) use all the skills related to nonverbal communication in a professional way, i.e., silence, space, visual contact, etc. (Grajales et al., 2014).

\subsection{Internal communication}

In health organizations, everything is related to communication: employees' behaviors, corporate values, patients' perceptions, building design, etc. (Rodrigues; Azevedo; Calvo, 2016). According to McCarroll et al. (2014), internal communication initiatives should not focus on creating final products such as newsletters, magazines, etc. but rather on defining strategic values and subsequently integrating them into the daily logic of all employees. Internal communication initiatives are essential for hospital credibility. First, internal communication allows hospitals to reinforce their internal processes through information sharing and helping employees to adapt to change (Rodrigues; Azevedo; Calvo, 2016). Second, via internal communication, hospitals can implement management initiatives, improve internal knowledge, promote corporate ideas, and reinforce value-added services (Medina-Aguerrebere, 2018a). Third, it develops an organization's corporate culture, allowing employees to work in an efficient way that is consistent with the main objectives of the company (Xie et al., 2013). Fourth, internal communication experts help hospitals improve their accuracy concerning scientific information addressed to employees, suppliers, and patients (Burleson, 2014). Fifth and finally, internal communication allows health professionals to reinforce the engagement of the company with its main stakeholders, especially patients (Pelitti, 2016).

Most health organizations have implemented an internal communication department where experts in communication, public health, and management define plans and protocols to communicate efficiently with internal stakeholders (Selt- 
zer et al., 2012). Working in a structured way allows experts in internal communication to legitimize this professional activity as a strategic asset for the company (Veltri; Nardo, 2013). To do this, they integrate quantitative and qualitative information related to stakeholders into all internal communication initiatives, such as their needs or expectations, in order to justify strategic decisions (Veltri; Nardo, 2013). Finally, they also constantly measure its efficiency in terms of employee behaviors, brand reputation, and adherence to internal changes (Kwateng; Osei; EkowAbban, 2014).

\subsection{External communication}

In health organizations, both internal and external communication initiatives are considered to be management tools with the main objective of optimizing the hospital's internal and external processes (Maier, 2016). According to Househ, Borycki, and Kushniruk (2014), health communication experts in both domains work in a multidisciplinary way and integrate ethics in each communication initiative. In this way, they are able to help health organizations reinforce their relationships with internal and external stakeholders in a professional way (Medina-Aguerrebere, 2018a).

Thanks to external communication, health organizations can influence the attitudes, behaviors, and expectations of patients (Becerra-Muñoz; Reina-Estévez; Victoria-Mas, 2015); in fact, when patients evaluate hospital quality, they consider many criteria related to communication initiatives (Johnson, 2014). Patients are true opinion leaders, which is why hospitals try to influence them through external communication initiatives (Becerra-Muñoz; Reina-Estévez; Victoria-Mas, 2015). For example, when hospitals define their brand architecture (identity, mission, vision, values, and culture), they work with patients and integrate their opinions into some strategic decisions (Kumar; Jacob; Thota, 2014). In this way, a hospital can build a brand collectively with its main stakeholders (Anisimova, 2013). On the other hand, collaborating with patients is also important when hospitals face a crisis, such as complaints from patients or employees (Medina-Aguerrebere, 2020). Managing a crisis involves evaluating its impact on the company's brand and implementing external communication initiatives to fix any reputation problems (Heide; Simonsson, 2014). In these situations, patients play an essential role, as they can contribute to the avoidance of misinformation (Mosquera; Meléndez; Latasa, 2015).

Implementing an annual corporate communication plan consistent with the company's brand architecture is mandatory before launching an external communication campaign

When hospitals implement an external communication strategy, they consider five main principles. First, strategic consistency: implementing an annual corporate communication plan consistent with the company's brand architecture is mandatory before launching an external communication campaign (Moreno; Wiesenberg; Verčič, 2016). Second, public health approach: hospitals prioritize pedagogical information allowing patients to improve their knowledge about treatments and diseases (Fischer, 2014). Third, opinions and attitudes: hospitals implement external communication campaigns to reinforce or change what patients think about health-related issues, but not to promote products or business (Robinson et al., 2014). Fourth, research: these organizations constantly monitor the attitudes of all their stakeholders concerning the company's products, services, or employees (Moser; Freeman, 2014). And fifth, monitoring: managing corporate communication involves constantly measuring its impact on different intangible values, such as the company's brand or stakeholder perceptions (Zerfass; Viertmann, 2017).

\section{Branding and reputation in hospitals}

A hospital organization develops its brand to enhance relationships with internal and external stakeholders and guarantee its survival in the health market (Medina-Aguerrebere, 2020). According to Esposito (2017), a brand represents different tangible and intangible assets, allowing the organization to create added value that determines what stakeholders think about the company. In other words, a hospital's brand refers not only to names and corporate colors but also to the experiences and perceptions of patients (Wang et al., 2011). The branding of an organization is a human process that influences the perceptions and opinions of stakeholders, which is why all companies need to build their brand along with their stakeholders in a collective way (Prochaska; Coughlin; Lyons, 2017).

Before implementing any corporate communication initiative, hospital organizations define their brand architecture: identity, values, mission, vision, and culture (Medina-Aguerrebere, 2018a). Identity refers to the main reasons why the company's founders decided to create the organization; in other words, identity is an intangible asset that helps the company take consistent decisions (Veltri; Nardo, 2013). Although the corporate communication department is in charge of defining this element, its practical implementation in the company is a collective responsibility assumed by all employees (Smith, 2017). This department defines and implements the visual identity elements, such as the logo, name, architecture, and verbatim, and all employees integrate these elements into their daily logic to disseminate the organization's identity though their behaviors (He; Balmer, 2013).

According to Sheehan and Isaac (2014), corporate values are directly related to identity, because they translate the abstract concept of identity into a more tangible reality that all employees can understand. Corporate values, such as excellence, ethics, or integrity, are powerful tools to influence employees and help them work in a consistent way (Ortega-Parra; Sastre-Castillo, 2013; Whiteley; Price; Palmer, 2013). The mission refers to the main objectives pursued by the company in the medium term (5-10 years). Each department in the hospital establishes its organizational objectives 
according to the mission in order to reinforce the hospital's main objectives (Cady et al., 2011). The vision establishes the long-term objectives defined by the company for the next 50 years, and acts as a motivational element for all employees (Singal; Jain, 2013). Finally, the corporate culture clearly establishes how employees must behave, both internally and externally, in order to create a unique company that is consistent with its brand architecture (Pinho; Rodrigues; Dibb, 2014). Thanks to this corporate culture, companies become more efficient as well as more credible (Ivanov; Sharman, 2018).

Hospital organizations define and implement all these corporate elements (identity, values, mission, vision, and culture) in a consistent way to improve their brand reputation (Nelson; Taylor; Walsh, 2014). Developing a powerful brand has become a priority for many health organizations due to the constant need to adapt to new internal and external changes, which represents a challenge from a corporate communication point of view (Kemp; Jillapalli; Becerra, 2014). To reinforce their brand, most organizations implement different research initiatives to better understand why stakeholders behave in a particular way and how they can integrate these behaviors with the hospital's brand (Garga et al., 2020). Once hospitals have analyzed all these research-related issues, they can update their brand architecture and define a brand positioning; in other words, they can establish a market niche in which they can become a true reference (Ruiz-Granja, 2015). This brand positioning should be consistent with the hospital's business plan and main strategic objectives, and should determine all the internal and external communication initiatives led by the hospital (Cua; Moffatt-Bruce; White, 2017).

Hospital branding constitutes a strategic communication initiative because it allows organizations to become credible companies and improve their internal functioning (González-Pacanowski; Medina-Aguerrebere; Medina, 2020). The following five realities justify this statement: (1) promoting a brand influences the emotional link established between patients and health professionals, as well as their communication relationships (Kemp; Jillapalli; Becerra, 2014); (2) thanks to branding campaigns, hospitals can integrate human values into their business logic and change the organization as well as its main medical services (Kotsenas et al., 2018); (3) branding campaigns are directly related to health education, which reinforces the credibility of hospitals as a source of medical information (Kotsenas et al., 2018); (4) thanks to branding, patients are more willing to share their opinions, and therefore hospitals can improve the quality of their healthcare service (Wu, 2011); finally, (5) branding initiatives activate a positive "word-of-mouth" effect, which helps hospitals to recruit new patients, employees, and investors (Esposito, 2017).

Implementing branding campaigns to improve reputation constitutes a priority for many hospitals in terms of medical service, management, and financial performance (Triemstra; Poeppelman; Arora, 2018). When hospitals enjoy a positive reputation among stakeholders, most patients trust the company because they associate it with high-quality medical care (Mira; Lorenzo; Navarro, 2014), which, in turn, influences their decisions to recommend the hospital to other patients (Noar et al., 2018). To improve their reputation, hospitals can implement different initiatives: (a) constant research and monitoring to evaluate stakeholder opinions regarding the hospital and its services and employees (Gay; Pho, 2013), (b) pedagogical initiatives to help patients understand how the hospital's brand can improve patient empowerment (Johnson, 2014), (c) learning initiatives, such as education centers or books published to help society change their health-related behaviors (Badr; Carmack; Diefenbach, 2015; Trepanier; Gooch, 2014), (d) internal campaigns to reinforce the participation of health professionals in branding campaigns that develop their own personal brand as experts in different scientific fields (Han et al., 2017), and (e) external campaigns to explain to stakeholders the hospital's engagement with employees, patients, and public authorities (Wæraas; Byrkjeflot, 2012).

\section{Reputation and social media in hospitals}

\subsection{Impact of social media on hospital corporate communication strategies}

Online platforms such as websites, social media, and mobile apps allow hospitals to energize their corporate communication strategies and reinforce their brand reputation (Fischer, 2014). These organizations integrate these platforms with the hospital's annual corporate communication plan (Ruiz-Granja, 2015) to build a credible brand from a scientific communication point of view (Fernández-Silano, 2013). Even though some hospitals lack the resources to implement professional management of social media in terms of team, budgets, software, etc. (Rando-Cueto; De-las-Heras-Pedrosa, 2016), they try to improve their social media presence in order to boost their relationships with stakeholders (Fernández-Luque; Bau, 2015).

Through the use of these platforms, hospitals can implement collective decision-making processes in order to integrate the attitudes and expectations of patients with the medical services provided by the hospital (Lim, 2016), enhance patient empowerment through the establishment of pedagogical initiatives focused on health education (Househ; Borycki; Kushniruk, 2014), improve patient-health professional relationships before, during, and after hospital consultations (Griffis et al., 2014), reinforce internal processes related to medical information and employee performance (Bubien, 2015), activate a positive "word-of-mouth" effect concerning the hospital's services and its health professionals' reputation (McCarroll et al., 2014), and implement public health campaigns to influence health-related behaviors (Matarín-Jiménez, 2015). 
Creating social media strategies constitutes a challenge for many hospitals due to the following three main reasons: (a) all content disseminated via these platforms should be adapted to the needs of each stakeholder in terms of the information and emotional support provided (McCarroll et al., 2014), (b) hospitals need to establish a corporate dialog with stakeholders focused on health-related content, not business-related content (Greysen; Kind; Chretien, 2010), and (c) organizations have to implement a professional research process to qualitatively and quantitatively evaluate the impact of social media on the hospital's brand (Bermúdez-Tamayo et al., 2013). To address all of these challenges, hospitals integrate social media initiatives into their annual corporate communication plan to create content that is consistent with their brand identity and main communication objectives (Blomgren; Hedmo; Waks, 2016). They also develop policies to help employees use these platforms in a professional way (Campbell; Craig, 2014), for example, explaining how to respect the main principles applied in medicine when using social media platforms (Greysen; Kind; Chretien, 2010).

\subsection{Health professionals and patients on social media}

Patients and health professionals use social media platforms to communicate health-related content such as treatments, diseases, research, etc. to the public (Medina-Aguerrebere, 2018a). Thanks to these online relationships, health professionals can help resolve some public health problems (Salathé et al., 2013), reduce inequalities in terms of access to medical services (Kim et al., 2016), and promote communication as a strategic asset in the health field (Peluchette; Karl; Coustasse, 2016). This is why many hospitals offer learning initiatives to improve the communication skills of health professionals on social media (Farnan et al., 2013) and teach them how to focus their online relationships towards the needs and expectations of patients (Haluza et al., 2016). According to Grajales et al. (2014), when these professionals use social media, they should respect the following four main principles: (a) be professional and focus on helping patients, (b) tell the truth and respect patient integrity, (c) ask for help from the communications department when needed, and (d) center online messages on patient needs in order to improve their engagement with the hospital.

Patients have become active social media users because they can search these platforms for medical information, contact other patients, and share personal experiences related to their treatment and disease (McCarroll et al., 2014). Although many patients complain about the lack of accuracy in some health-related content disseminated on social media platforms (Kim et al., 2016), most of them use social media for emotional support (Myrick et al., 2016). Thanks to these platforms, patients can establish a more symmetrical relationship with health professionals, opening up a dialog in a more cordial way (Smailhodzic et al., 2016). Social media platforms determine a patients' attitude and skills (Namkoong et al., 2017), prompting several authors, such as Glover et al. (2015), to claim that hospitals should provide training on how to use social media for making health decisions.

\section{Patients and doctors should improve the way in which they use social media pro- fessionally and ethically within a health environment}

Both patients and health professionals appreciate social media as a tool that is useful for communicating via different formats and with many people at the same time (Antheunis; Tates; Nieboer, 2013). Nevertheless, both should improve the way in which they use social media professionally and ethically within a health environment (Moorhead et al., 2013). Health professionals, patients, and hospitals should work together to rethink the concept of online health and define a professional context where sharing medical knowledge and emotional experiences constitutes a true asset that can determine all medical services (Visser et al., 2016). In other words, hospitals should take advantage of social media to reinforce participative medicine (Myrick et al., 2016) and propose new medical services (Badr; Carmack; Diefenbach, 2015).

\subsection{Social media as a branding tool for hospitals}

Social media platforms have become a corporate communication tool with the ability to influence stakeholder perceptions of a hospital's brand, services, and employees (Medina-Aguerrebere, 2018a). For example, when patients rate a hospital's brand, they consider several factors related to treatments and diseases, but also to its social media presence -medical information, emotional support, etc. (Huesch; Currid-Halkett; Doctor, 2014). According to several authors such as Bardach et al. (2013), patient satisfaction is directly related to how hospitals use social media to communicate and how they integrate these platforms with medical services; For example, some hospitals use social media and mobile apps to reinforce the security of their medical services (Greaves et al., 2013), while other hospitals use these platforms to disseminate content focused on positive emotions to change patient perceptions of treatments (López-Bolás; Valderrama-Santomé; Di-Virgilio, 2019). Nevertheless, hospitals should also consider some medical risks related to social media, such as the lack of corroboration when patients post content, or the difficulty in managing the quantity of messages from patients (Lagu et al., 2016).

Hospitals cannot control all the content posted on social media platforms, because patients, families, and other stakeholders also actively participate on these platforms (Miller; Tucker, 2013); they can only analyze the market and stakeholder perceptions to predict people's reactions (Park; Rodgers; Stemmle, 2013). By so doing, they can disseminate accurate and up-to-date information that is useful for both stakeholders (Gurau, 2013) and the hospital's brand reputation (Tsimonis; Dimitriadis, 2014). When hospitals establish a dialog that is useful for both themselves and stakeholders, they enhance their legitimacy as providers of assistance, research, and teaching (Blomgren; Hedmo; Waks, 2016). Furthermore, this dialogue allows hospitals to build an online community through which health professionals and patients can 
share brand-related content (Lim, 2016), thereby improving patient empowerment (Rupert et al., 2014). These brand communities are essential to build a reputation with more stakeholders (Laroche; Habibi; Richard, 2013).

The most popular social media platforms used by hospitals are Facebook, Twitter, and YouTube. Thanks to Facebook, hospitals can improve stakeholder engagement with the company (Richter et al., 2014), patient access to personal experiences related to treatments, diseases, or symptoms (Gage-Bouchard et al., 2017), and employee access to corporate information such as annual plans, protocols, or strategic plans (Glover et al., 2015). Facebook has completely changed how hospitals communicate, especially due to its immediacy and variety of formats (Lee et al., 2015). In other words, Facebook has become a strategic tool to improve hospital branding (Yang et al., 2018); for example, $80 \%$ of users prefer to be reached via this platform, not through companies' corporate websites (Brent, 2016).

Facebook has become one of the most important social media platforms used by cancer hospitals to improve their online reputation Patients also appreciate this platform and use it to contact health professionals and ask them for medical services, which forces hospitals to become online companies (Lee et al., 2015). Moreover, Facebook offers several key performance indicators that are useful for evaluating brand performance (Attai et al., 2016). Thanks to all of these data and metrics, companies can integrate Facebook as a professional tool for corporate communication (Kotsenas et al., 2018), which is a smart decision from an economic point of view as there is a positive relationship between patient engagement on Facebook and hospital revenues (Apenteng et al., 2020).

Concerning Twitter, many organizations use this platform to improve their public image, disseminate corporate information, establish better relationships with patients, and boost medical services (Rando-Cueto; De-las-Heras-Pedrosa, 2016). This platform allows hospitals to revitalize corporate communication (Boudewyns; Himelboim; Hansen, 2015) and become sources of medical information about treatments and diseases (Park; Reber; Chon, 2016). On Twitter, hospitals can build a brand community and reinforce a patient's social needs, such as their emotional support or social integration (Triemstra; Poeppelman; Arora, 2018). On the other hand, health professionals also participate in these communities and integrate Twitter into their daily life to improve the medical services offered to patients (Antheunis; Tates; Nieboer, 2013). Finally, with regard to YouTube, this platform plays a fundamental role in hospitals' corporate communication because, on the one hand, it allows them to disseminate health education videos and reduce patient anxiety (Huang, 2013), while on the other hand, it permits hospitals to understand patient knowledge of health-related content (Balasooriya-Smeekens; Walter; Scott, 2015).

\section{Cancer hospital reputation dissemination through social media}

\subsection{Communication between health professionals and cancer patients}

Cancer patients consult complex information systems that allow them to better understand their disease and treatments (Han et al., 2017). When they interact with health professionals, they want to take part in some medical decisions (Peterson et al., 2016). These patients build an image of their doctors centered around their expertise and authority, but also their collaboration with patients when taking health decisions (Beesley et al., 2016). For this reason, cancer patients greatly appreciate health professionals who emphasize their decisions and consider the patients' point of view (Salmon; Bridget, 2017).

According to several authors such as Epstein, Duberstein, and Fenton (2017), universities need to change their study plans to provide students with communication skills training, in other words, training on how to communicate interpersonally with different types of patient. This kind of communication cannot be reduced to technical skills; physicians also need to be trained in emotional and social communication issues (Salmon; Bridget, 2017). Moreover, professionals should also attend courses centered around how to present facts to patients and individualize their answers in order to respect patients' emotions (Moore et al., 2018).

When cancer patients and health professionals interact in hospitals, they respect the following six core principles: (1) managing uncertainty, (2) responding to emotions, (3) making decisions, (4) fostering healing relationships, (5) enabling self-management, and (6) exchanging information (Blanch-Hartigan et al., 2016). Cancer patients, as well as their relatives, have a high incidence of psychological stress, which can be minimized by effective communication skills from health professionals (Moore et al., 2018). In other words, interpersonal communication skills from health professionals directly influence their patients' quality of life, as well as their engagement with their own treatment, and their capacity to answer questions (Epstein; Duberstein; Fenton, 2017). In cancer hospitals, optimal communication between patients and physicians depends on a physician's regulation of emotions, which is directly related to both physician (stress and alexithymia) and patient characteristics (sadness and anxiety) (De-Vries et al., 2018).

In cancer hospitals, health professionals interact not only with patients but also with three other strategic stakeholders as well: the patient's family, other health professionals, and the children of the cancer patient. First, the patient's family. Communication is an important process through which a family can make sense of the cancer, engage in social support, negotiate role changes, and coordinate coping mechanisms, which is why health professionals should also interact with the patient's family (Badr, 2017). These interactions may influence the patient's level of satisfaction, as well as other 
important aspects such as their quality of life, level of pain, and physical wellbeing (Langer et al., 2018). Second, health professionals. Cancer experts communicate with other oncologists, as well as with primary care physicians, about post-treatment status and care recommendations for cancer patients (Klabunde et al., 2017).

These communicative relationships are based on past experiences, but also on data related to patient behavior and health professionals' expectations (Beesley et al., 2016). And third, the children of the cancer patient. Communicating with children raises some challenges, such as giving too much or too little information, avoiding certain topics, or establishing mechanisms to improve patient trust in the hospital (Keim et al., 2017).

\subsection{Cancer hospitals' corporate communication}

Social media platforms offer the ability to engage entire populations at low cost, connect patients with providers, encourage adherence to cancer care, and collect vast quantities of data for cancer research (Prochaska; Coughlin; Lyons, 2017). In the USA, more than $95 \%$ of the top-ranked hospitals use social media as a corporate communication tool. Most patients appreciate these platforms as a source of medical information and emotional support, even if they sometimes complain about the technical language used by health professionals (De-las-Heras-Pedrosa et al., 2020).

When cancer hospitals communicate through social media platforms, they respect two main values: social support and trust (Namkoong et al., 2017). Although disseminating accurate, up-to-date information constitutes a priority for health organizations (Han et al., 2017), building trust with all their stakeholders is still more important, because it allows hospitals to improve their brand's credibility (Smith, 2017). On the other hand, and according to authors such as Kotsenas et al. (2018), social media platforms are consistent with traditional mechanisms of knowledge diffusion in medicine because they allow health professionals to be informational protagonists and play an active role. This is why hospitals should prioritize social media, firstly by fixing some problems such as the lack of privacy and confidentiality, the potential for inaccurate medical advice, the propagation of dangerous health behaviors, and information overload (Attai et al., 2016).

From a corporate communication point of view, the use of social media offers several advantages for cancer hospitals: (a) these platforms allow hospitals to innovate and revitalize their corporate communication strategies (Vraga et al., 2018), (b) hospitals can focus on storytelling and pedagogical communication initiatives in order to improve engagement with patients (Kotsenas et al., 2018), (c) hospitals can enhance engagement with health education and prevention initiatives (Noar et al., 2018), (d) hospitals can use social media to improve their public health communication campaigns, especiaIly in crisis situations (Miller; Guidry; Fuemmeler, 2019), (e) health organizations can use social media to reduce social inequalities between patients in different countries (De-las-Heras-Pedrosa et al., 2020), (f) integrating social media platforms with oncological care can potentially improve patient care and increase trust (Sedrak et al., 2017), (g) the use of social media allows health professionals and patients to interact before and after their hospital appointments (Yang et al., 2018), (h) these platforms provide hospitals with data that allows them to adapt their medical services to different patients (Triemstra; Poeppelman; Arora, 2018), (i) social media can improve patient outcomes by offering knowledge about diseases and promoting lifestyle modifications (Yang et al., 2018), and (j) professional management of social media platforms can help hospitals improve their financial performance by facilitating customer service and providing a low-cost marketing platform (Apenteng et al., 2020).

Most hospitals use social media platforms to launch their own brand communities (Medina-Aguerrebere, 2018a) in order to help patients find emotional support, participate in learning initiatives, and interact with health professionals (Falisi et al., 2017). Interacting with other patients suffering from the same disease plays a key role in patient satisfaction, as well as in their empowerment (Garga et al., 2020). In some countries such as Spain, many patient associations have considered the difficulties of accessing certain health-related content disseminated via social media (technical concepts, diversity of existing issuers, etc.) and recommend that patients participate in hospital brand communities where health professionals are involved in helping patients understand medical concepts (De-las-Heras-Pedrosa et al., 2020). In the USA, for example, the Mayo Clinic has implemented a social media strategy with the objective of improving patient care, advancing medical research, and expanding education through their online community (Kotsenas et al., 2018), instead of aiming to accelerate marketing initiatives.

To improve their brand's reputation properly through social media, cancer hospitals base their strategies on two main values: research and metrics. Cancer hospitals carry out research on patient perceptions and attitudes before implementing any social media campaigns (Noar et al., 2018) because these data can improve their strategic decisions in terms of targets, objectives, and brand positioning (Mazor et al., 2016). Hospitals implement research mechanisms that allow them to identify the relationships established between the hospital's social media presence, the consumer's health behavior, and the hospital's profitability (Apenteng et al., 2020). On the other hand, before launching social media campaigns, hospitals define different key performance indicators to use during and after the campaign to evaluate its efficiency (Cua; Moffatt-Bruce; White, 2017). Thanks to these metrics, organizations can engage with their customers, improve business performance, and legitimize online initiatives as a professional activity in the corporate communication field (Garga et al., 2020). 
Health professionals should recognize the importance of owning their brand, protecting their reputation, and promoting their hospital's brand credibility (He; Balmer, 2013). Improving a hospital's reputation is one of the most important objectives that all hospitals should try to achieve when using social media as a corporate communication tool (Ivanov; Sharman, 2018). In this context, reputation is related to stakeholder perceptions of the hospital's credibility as a source of medical information (Costa-Sánchez; Míguez-González, 2018). All strategies used on social media should be consistent with the hospital's annual corporate communication plan in order to reinforce the brand of the hospital as a health provider (Medina-Aguerrebere, Gonzalez-Pacanowski; Medina, 2020). Using social media in a professional way constitutes a true challenge because, according to several authors such as Triemstra, Poeppelman, and Arora (2018), a hospital's reputation is influenced by its social media presence. Via these platforms, hospitals can share different corporate elements such as profiles of health professionals, main medical services, and the hospital's history or ranking (Cua; Moffatt-Bruce; White, 2017). Nevertheless, they must prioritize the most useful content to build a credible brand in the long term (Gage-Bouchard et al., 2017).

\subsection{Corporate communication with cancer patients through social media}

Hippocrates' admonition and the lack of understanding by health professionals about corporate communication have led many hospitals around the world to avoid the use of social media platforms (Kotsenas et al., 2018). Nevertheless, these platforms play a key role in explaining the various medical services that the hospital offers and helping patients to reinforce their self-confidence (Han et al., 2017). Using social media as a public health tool for patient empowerment has become a true opportunity for health professionals to improve their personal brand and enhance their hospital's reputation (Salmon; Bridget, 2017). For this reason, cancer hospitals should implement evidence-based practices on social media platforms to improve the way in which health professionals use these platforms (Sedrak et al., 2017).

Many cancer hospitals integrate social media platforms with patients' daily logic to improve their satisfaction before and after hospital visits (Falisi et al., 2017). Thanks to social media, patients can improve their skills in health education; for example, they can consult informative videos on YouTube, read about healthy behaviors on Facebook, or participate in public health campaigns on Twitter (Kotsenas et al., 2018). Health professionals should improve their online communication skills to become a source of medical information and reinforce their relationships with patients. In other words, health professionals should become brand ambassadors (Yang et al., 2018). Social media platforms have become a strategic asset, allowing health organizations to improve their professional employees' skills from a communication and medical point of view (Kotsenas et al., 2018).

Increasing numbers of patients are using social media platforms to improve their skills in health education and reinforce their medical decisions (Medina-Aguerrebere, González-Pacanowski; Medina, 2020). These platforms allow patients to better understand why health professionals behave in a certain way when interacting in a hospital environment (Sedrak et al., 2017). Moreover, the use of social media has also changed how patients approach cancer treatments and what they think about cancer hospitals (Attai et al., 2016). Nevertheless, some patients have identified various barriers that stop them from utilizing social media, such as technical concepts related to cancer treatments or protocols applied in hospitals (De-las-Heras-Pedrosa et al., 2020). Regardless of this content, many patients have learned to convey their emotions better through social media, especially positive emotions such as hope, joy, or humor (Cho et al., 2018). These emotions influence how they face their cancer and how they interact with their family and friends (Vraga et al., 2018); For example, and according to Namkoong et al. (2017), breast cancer patients who perceive less online social support have a larger social network on social media platforms, but they tend to use them less actively when their family and friends reinforce their emotional needs sufficiently.

\subsection{Facebook and cancer hospitals}

Facebook has become one of the most important social media platforms used by cancer hospitals to improve their online reputation (Triemstra; Poeppelman; Arora, 2018). Health professionals resort to this platform to communicate with cancer patients about six main topics: (a) the cancer journey, (b) the emotional strains associated with caregiving, (c) awareness about pediatric cancer, (d) fundraising, (e) research support, and (f) gratitude for support (Gage-Bouchard et al., 2017). Thanks to Facebook, these professionals understand why cancer patients behave in a particular way (Fernández-Gómez; Díaz-Campo, 2016). Health professionals use Facebook to help patients improve their empowerment, but also to enhance their own personal brand from a social and scientific point of view (Medina-Aguerrebere, González-Pacanowski; Medina, 2020). To do so, they focus conversations with patients on three main topics: (1) general health issues, (2) personal and professional projects, and (3) corporate innovations that encourage public involvement (Costa-Sánchez; Míguez-González, 2018).

By using Facebook, hospitals can revitalize their brand from an economic and corporate point of view (Miller; Guidry; Fuemmeler, 2019). The following five reasons support this statement: (1) According to data provided by Facebook, hospitals can improve their knowledge of the relationships established with patients, and design messages based on patients' interests and demographics, directly influencing the hospital's credibility (Kotsenas et al., 2018); (2) Facebook is a source of emotional support for all caregivers specialized in cancer, as well as for patients and their family members (Gage-Bouchard et al., 2017); (3) thanks to Facebook, many patients can interact directly with oncologists and obtain credible information, thus positively influencing patient empowerment, as well as their perceptions of the hospital's 
brand (Attai et al., 2016); (4) Facebook plays a key role in patient evaluation of a hospital's quality and reputation (Ivanov; Sharman, 2018); and finally, (5) Facebook positively influences patient engagement which, in turn, determines economic investment in the hospital (Apenteng et al., 2020).

Social media managers working in cancer hospitals focus their activities on the implementation of online strategies, but also on doing research. In other words, they identify patient needs and expectations concerning the hospital, its medical services, and employees (Fernández-Gómez; Díaz-Campo, 2016). Promoting social media platforms as a research tool for corporate communication purposes involves several issues: implementing a research unit into the social media department, recruiting experts in social sciences, producing protocols and plans to coordinate the hospital's campaigns, and integrating this research logic into the communication initiatives launched on Facebook (Medina-Aguerrebere, González-Pacanowski; Medina, 2020). Thanks to data provided by Facebook, social media managers can interact with patients in new ways: stimulating patient interest in clinical trials, carrying out simulations of cancer treatments and visits to the hospitals, allowing patients to interact with doctors directly, and integrating patient ideas into some strategic decisions (Sedrak et al., 2017). Although most hospitals specialized in cancer use their Facebook corporate profile to attract patients, employees, and investors (Yang et al., 2018), these organizations should not only focus on business but also on the pedagogical insights needed by patients so they can take efficient decisions concerning their treatment (Gage-Bouchard et al., 2017).

\subsection{Twitter and cancer hospitals}

Cancer hospitals can also use Twitter for branding initiatives, even if it poses some problems concerning coercive content and privacy policies (Sedrak et al., 2017). When health professionals interact with cancer patients via this platform, they tend to focus their conversations on different medical topics such as treatments, diseases, and corporate projects led by the hospital (Costa-Sánchez; Míguez-González, 2018). Most patients use Twitter for emotional support, but also for establishing contact with other patients about cancer-related content (Sedrak et al., 2017).

According to several authors, such as Park, Reber, and Chon (2016), Twitter is a powerful tool for creating cancer-specific online communities composed of diverse stakeholders including patients, families, healthcare providers, advocates, and policymakers. Through these communities, hospitals can improve stakeholder engagement and help health professionals develop health education initiatives, such as online journal clubs about cancer treatments (Sedrak et al., 2017). By meeting patients through an online community, health professionals can correct misinformation and redirect them to accurate and reliable sources of medical information (Prochaska; Coughlin; Lyons, 2017).

Hospital organizations can integrate Twitter as a corporate communication tool into their protocols for many types of cancer, e.g., lung and reproductive cancers. According to Sutton et al. (2018), many patients suffering from lung cancer use Twitter to communicate about modifiable cancer risk factors or cancer prevention, but not about treatments, end of life, or unknown phases. Many patients refuse to post personal information and prefer only to read information provided by health organizations, especially hospitals (Miller; Guidry; Fuemmeler, 2019). Media companies need to improve their communication strategies through Twitter in order to become more credible, and to do that, they must disseminate information with added value that can be easily retweeted (Sutton et al., 2018).

On the other hand, Twitter has become a powerful communication tool for hospitals specializing in women and men's reproductive cancers. Normally, these organizations focus on awareness and support, rather than concrete actions and behaviors, as many patients require accurate information and want to participate in active communities based on reliable knowledge (Vraga et al., 2018). The use of Twitter allows hospitals to improve patient understanding of treatments and diseases and improves patient engagement with their own welfare (Basch et al., 2015).

\subsection{YouTube and cancer hospitals}

Increasing numbers of cancer hospitals are developing corporate profiles on visual platforms such as YouTube, Flickr, Instagram, and Pinterest (Medina-Aguerrebere, González-Pacanowski; Medina, 2020). Thanks to such visual communication on social media, health organizations can improve patient empowerment and facilitate the implementation of collective decision-making processes between patients and oncologists. Nevertheless, these companies need to recruit experts in health communication to produce an accurate visualization of cancer (Basch et al., 2015). The use of images to explain the main consequences of and treatments for different cancers is one of the most efficient strategies that these organizations can implement on social media to generate visibility and credibility (Fernández-Gómez; Díaz-Campo, 2016). For example, and according to Cho et al. (2018), many hospitals use Instagram to educate patients about melanoma and the main consequences of and treatments for it, thus positively influencing patient understanding and their adherence to the treatment.

Several authors, such as Míguez-González, García-Crespo, and Ramahí-García (2019), have carried out quantitative analysis to prove that YouTube is an efficient tool to disseminate visual information related to cancer, although there have been some complaints of videos being created by nonqualified individuals, and others that are not useful from a medical point of view. YouTube is not only

YouTube is not only an efficient corporate communication tool, but also a research platform as well 
an efficient corporate communication tool, but also a research platform as well. In other words, YouTube allows hospitals to better understand how cancer patients build their own representation of their cancer (Balasooriya-Smeekens; Walter; Scott, 2015). Understanding these representations is useful to satisfy all patient needs, especially in an emotional sense. For many patients, the experience of cancer is directly associated with negative emotions of fear, anger, and sadness, prompting youtubers to produce videos based on hope and positivity (Balasooriya-Smeekens; Walter; Scott, 2015). However, this emotionally based approach is not shared between all hospitals, public authorities, or patient associations, because they consider it better to focus on content and useful insights (Míguez-González; García-Crespo; Ramahí-García, 2019).

YouTube allows hospitals to revitalize their corporate communication with cancer patients and implement various innovative initiatives, such as pedagogical videos about treatments, medical protocol tutorials, or 3D informational graphics related to different cancers (Huang, 2013). The use of YouTube as a corporate communication tool permits these organizations to become sources of medical information based on images and videos (Lagu et al., 2016). In some cases, e.g., for breast cancer, this medical information is especially important for patients to improve their empowerment and welfare (Cho et al., 2018). Patients suffering from breast cancer can access many videos in this domain, and most of these videos, according to Míguez-González, García-Crespo, and Ramahí-García (2019), have the following five main characteristics: (1) the main topics are prevention and early detection, (2) videos produced by health organizations focus on mammograms, while those produced by individuals prioritize patient experiences, (3) there are a great variety of people producing these videos, such as hospitals, youtubers, media companies, etc., (4) videos about patients' experiences are more popular than those centered around medical information, and (5) most patients use YouTube for emotional reasons, not for learning about treatments or prevention.

YouTube, Facebook, and Twitter are strategic platforms that can improve a hospital's reputation as well as its relationships with internal and external stakeholders (Medina-Aguerrebere, González-Pacanowski; Medina, 2020). Nevertheless, cancer hospitals should not use social media platforms for doing business, but rather for implementing public relations initiatives with the main objective of satisfying patient needs in terms of information and emotional support (Miller; Guidry; Fuemmeler, 2019). Applying this approach involves several issues: (1) hospitals should analyze how information can help patient empowerment and subsequently plan their content strategy on different corporate social media platforms (Triemstra; Poeppelman; Arora, 2018), (2) communicating about cancer should be perceived as an opportunity to build a new image of the disease, allowing patients to face their treatments in a more positive, constructive way (Vraga et al., 2018), (3) hospitals become human brands with the main objective of integrating human values such as confidence, respect, or multiculturalism into cancer treatment (Medina-Aguerrebere, 2018a), and finally (4) cancer hospitals use social media platforms to change the mentalities of health professionals, as well as the hospital's internal and external processes to build a new medical service that is more focused on patient's needs (Noar et al., 2018).

\subsection{Other social media platforms and cancer hospitals}

Besides Facebook, YouTube, and Twitter, hospitals can also manage other social media platforms if they consider them to be consistent with their strategic communication interests. In May 2020, the most popular social media platforms were Facebook, YouTube, WhatsApp, Facebook Messenger, WeChat, Instagram, TikTok, QQ, Qzone, Sina Weibo, and Reddit (Oberlo, 2020). Facebook Messenger is an online app, while WeChat, QQ, QZone, and Sina Weibo are only available in China. Nevertheless, hospitals can use WhatsApp, for example. According to De-Benedictis et al. (2019), this platform is widely used by hospitals because doctors consider it to offer various advantages in clinical practice. Moreover, it is also useful for patient interaction. WhatsApp has become a safe, efficient option for internal communication within hospitals, even in emergency situations (Drake et al. 2016). Hospitals can also implement corporate communication strategies via Instagram, as it is a powerful tool that promotes visual education through different formats and initiatives (Kamel-Boulos; Giustini; Wheeler, 2016), and thanks to visual storytelling campaigns disseminated via the app, hospitals can foster informational and social support for vulnerable patients (Gurrieri; Drenten, 2019). Meanwhile, TikTok is an interesting platform with the potential for innovation in health education and improvement of patient engagement. In fact, the most widely viewed videos are about health behaviors and medical knowledge (Zhu et al., 2020). On Reddit, many patients are willing to share personal experiences with disease on this platform, despite possible privacy issues (Foufi et al., 2019), whence the importance of using this platform, at least for some particular patients. Finally, although not mentioned in the previous ranking, Pinterest and Flickr are also worth mentioning. Through Pinterest, hospitals can improve the patient experience by using Big Data to expand their knowledge about their own health (Shipley; Chakraborty, 2019). Flickr allows hospitals to dynamize their branding communication initiatives thanks to the dissemination of photos and the ability to share a collective experience (Medina-Aguerrebere, 2018b).

\section{Managing social media platforms as cor- porate communication tools is an oppor- tunity to improve hospitals' reputation and the interpersonal communication skills of health professionals}




\section{A proposal for a model to manage cancer hospitals' reputations on social media}

Managing social media platforms as corporate communication tools is an opportunity to improve hospitals' reputation and the interpersonal communication skills of health professionals. This process must include strong principles and evidence-based protocols that allow organizations to work consistently; otherwise, the creation of an unambiguous brand is impossible. For this reason, we propose herein the MedPac Model for Building Cancer Hospital Brands. We split this model into the following four main steps: (a) the Social Media Unit, (b) online communication principles, (c) annual content plan, and (d) key performance indicators.

\subsection{Social Media Unit}

The hospital's Corporate Communication Department must create a unit specialized in social media where different experts in corporate communication, public health, medicine, engineering, and mathematics work in an integrated way. Oncologists must not confuse the roles of information provider and care provider (Dizon et al., 2012), hence it is important that experts in communication lead this department. All these employees are led by the Social Media Manager, an expert in corporate communication whose main responsibility is to fix business problems through online communication strategies. To do this, they must define and implement an annual social media communication plan, as well as different protocols (crisis situations, press conferences, etc.). They must also define some key performance indicators to evaluate both employee performance on social media and the efficiency of hospital campaigns via these platforms. Working with data and quantitative indicators is essential for the implementation of efficient social media campaigns that allow cancer hospitals to improve their brand's credibility (Salmon; Bridget, 2017).

The main responsibility assumed by the Social Media Manager is to fix business problems through online communication strategies

One of the most important responsibilities assumed by the Social Media Manager is the creation of a brand ambassador structure. In other words, they should identify key employees in all medical and administration departments and train them in areas such as social media skills, brand architecture, or scientific divulgation techniques. The Social Media Unit communicates with the hospital's internal and external stakeholders through different brand ambassadors to activate a dialog and reinforce the brand community. Brand ambassadors play a key role in online corporate communication, as they help organizations become more credible and boost the corporate dialog between the company and its stakeholders (Maier, 2016).

This public relations approach for managing social media platforms prioritizes people, not corporations, and it is consistent with human values, patient empowerment, and participative medical initiatives. Despite this altruistic logic, the Social Media Manager must also help all brand ambassadors keep an updated log of their social media performance to adapt the hospital's corporate communication strategy to the needs and perceptions of stakeholders. Working with brand ambassadors is a useful way to improve the hospital's reputation, as well as engagement with stakeholders, especially patients and employees (Yang et al., 2018).

\subsection{Online communication principles}

The Social Media Unit's employees, as well as all brand ambassadors, must work in an integrated fashion and respect the ten online communication principles that will allow the hospital to become an unambiguous, credible brand (see Table 2 . Online communication principles). First, brand architecture. This corporate element is a reference for all communication initiatives led by the organization (Kumar; Jacob; Thota, 2014), hence all these initiatives should be consistent with the hospital's identity, mission, vision, values, and culture. Second, human brand. Communicating with stakeholders through social media requires hospitals to respect human values such as ethics, diversity, and patient integrity (Prochaska; Coughlin; Lyons, 2017). Third, pedagogical approach. Hospital organizations use social media to satisfy stakeholder needs in terms of informational and emotional support. To do this, they prioritize a learning approach based on knowledge that is useful to stakeholders (Gage-Bouchard et al., 2017). Fourth, emotions. All social media campaigns should consider that cancer patients face a difficult, emotional situation, hence the need for these organizations to integrate this emotional approach into their strategic decisions concerning online communication campaigns (De-Vries et al., 2018). Fifth, dialog centered on health-related content. Hospitals focus on meaningful content in order to create a platform that allows stakeholders to discuss health-related topics with experts from different health-related disciplines (Blomgren; Hedmo; Waks, 2016).

Table 2. Online communication principles

\begin{tabular}{|c|l|l|}
\cline { 2 - 3 } \multicolumn{1}{c|}{} & \multicolumn{1}{c|}{ Principle } & \multicolumn{1}{c|}{ Reference } \\
\hline 1 & Brand architecture & Kumar; Jacob; Thota, 2014 \\
\hline 2 & Human brand & Prochaska; Coughlin; Lyons, 2017 \\
\hline 3 & Pedagogical approach & Gage-Bouchard et al., 2017 \\
\hline 4 & Emotions & De-Vries et al., 2018 \\
\hline 5 & Dialogue & Blomgren; Hedmo; Waks, 2016 \\
\hline 6 & Innovation & Greysen; Kind; Chretien, 2010 \\
\hline 7 & Creativity & He; Balmer, 2013 \\
\hline 8 & Visualization & Basch et al., 2015 \\
\hline 9 & Accuracy & Burleson, 2014 \\
\hline 10 & Participative medicine & Myrick et al., 2016 \\
\hline
\end{tabular}


Sixth, innovation. Hospitals disseminate innovative insights about treatments, diseases, and prevention to prove to stakeholders the importance of the organization for society's wellbeing (Greysen; Kind; Chretien, 2010). Seventh, creativity. All organizations should take advantage of social media to reinforce their creative style and disseminate unique content in different formats such as video, text, or infographics (He; Balmer, 2013). Eighth, visualization. Hospitals promote visualization as a strategic asset that will allow stakeholders to better understand health-related content (Basch et al., 2015). Ninth, accuracy. Hospitals become experts in disseminating accurate scientific content that all stakeholders can understand and apply in their daily life (Burleson, 2014). Tenth, participative medicine. Thanks to social media, experts in health and communication reinforce patient empowerment and knowledge, therefore facilitating their interaction with health professionals (Myrick et al., 2016).

\subsection{Annual content plan}

The Social Media Manager must define an annual corporate content plan based on the hospital's brand architecture, as well as the six groups of brand ambassador, the five targets, the eight key messages, and the three social media platforms (see Table 3. Annual content plan). Concerning the brand architecture, the Social Media Unit should focus on one corporate element each month to reinforce stakeholder perceptions of the hospital brand. In other words, the Social Media Unit implements different communication initiatives (videos, online consultations, etc.) related to the brand architecture to explain each corporate element in a subtle, credible way. Once they have defined an annual content plan according to the brand architecture, they train six groups of brand ambassadors (hospital CEO, oncology director, oncology doctors, oncology nurses, oncology social workers, and other health professionals) about how to disseminate these elements through cancer-related content. In this way, the Social Media Unit does not interact with the final targets but rather trains brand ambassadors, therefore positively influencing the hospital's credibility. Concerning targets, the hospital prioritizes patients, patients' families, patient associations, public authorities, and media companies, because they have the potential to become opinion leaders with the ability to influence the perceptions of other stakeholders regarding the hospital's brand. As for key messages, all the online communication campaigns should aim to create a reputable brand, and to do this, the Social Media Unit should develop some strategic values that allow people to associate the hospital with a reputable brand: responsibility, professionalism, integrated services, credibility, innovation, and emotional support. Finally, concerning the social media platforms, cancer hospitals mainly use Facebook, YouTube, and Twitter, as well as their corporate website. In some cases, they may also integrate mobile apps to improve their visibility on some social media platforms. Social media is a powerful tool for cancer communities, allowing the use of real-world data for qualitative research, as well as valuable discussions about treatments and pathologies (Freedman et al., 2016). Among all social media platforms, Twitter is especially important for cancer patients to share psychological support (Sugawara et al., 2012), YouTube is useful in building a new image of cancer that helps empower cancer patients (Chou et al., 2011), and Facebook facilitates relationships between cancer patients and oncologists (Gage-Bouchard et al., 2017).

Table 3. Annual content plan

\begin{tabular}{|l|l|l|l|l|l|}
\hline \multicolumn{1}{|c|}{ Month } & \multicolumn{1}{|c|}{$\begin{array}{c}\text { Brand } \\
\text { architecture }\end{array}$} & \multicolumn{1}{|c|}{$\begin{array}{c}\text { Group of brand ambas- } \\
\text { sador }\end{array}$} & \multicolumn{1}{|c|}{$\begin{array}{c}\text { Social media } \\
\text { platform }\end{array}$} \\
\hline January & Identity & Hospital's CEO & Public authorities & Responsibility \\
\hline February & Value 1 & Oncology nurses & Patients & Professionalism \\
\hline March & Value 2 & Other health professionals & Patients & Integrated services & Twitter \\
\hline April & Mission & Oncology director & Media companies & Credibility \\
\hline May & Vision & Oncology doctors & Patient associations & Innovation \\
\hline June & Culture & Oncology social workers & Patients' families & Emotional support & Facebook \\
\hline July & Identity & Hospital's CEO & Public authorities & Responsibility \\
\hline August & Value 3 & Oncology nurses & Patients & Ethics \\
\hline September & Value 4 & Other health professionals & Patients & Patients'integrity & Twitter \\
\hline October & Mission & Oncology director & Media companies & Credibility \\
\hline November & Vision & Oncology doctors & Patients associations & Innovation \\
\hline December & Culture & Oncology social workers & Family patients & Emotional support & Facebook \\
\hline
\end{tabular}

\subsection{Key performance indicators}

Throughout the year, the Social Media Manager should monitor the hospital's social media presence on Facebook, Twitter, and YouTube to evaluate the brand's performance according to the different key performance indicators. Using quantitative and qualitative information to evaluate social media campaigns is a priority as well as an opportunity to improve stakeholder perceptions (Heide; Simonsson, 2014). Thanks to specific data, hospitals can reduce the risk related to strategic decisions concerning targets, creative concepts, media plans, or communication ob-

Using quantitative and qualitative information to evaluate social media campaigns is a priority as well as an opportunity to improve stakeholder perceptions 
jectives (Gay; Pho, 2013). Hospitals can follow the following seven principles proposed by the International Association for the Measurement and Evaluation of Communication (2020): (1) set precise goals, (2) identify outputs, outcomes, and potential impact, (3) define how these outcomes impact each stakeholder, (4) apply both qualitative and quantitative measurement techniques, (5) understand the impact of communication under different approaches, (6) apply a holistic approach, and (7) respect integrity and transparency. According to the MedPac Model for Building Cancer Hospital Brands, hospitals should use 15 performance indicators related to visibility, engagement, loyalty, recommendation, and efficiency (see Table 4. Performance indicators):

Table 4. Performance indicators

\begin{tabular}{|l|l|l|l|}
\cline { 2 - 4 } \multicolumn{1}{l|}{} & Facebook & Twitter & YouTube \\
\hline Visibility & Number of impressions & Average amount of impressions & Total video views \\
\hline Engagement & Number of likes & Average engagement rate & Video engagement \\
\hline Recommendation & Positive or negative comments & Positive or negative comments & Positive or negative comments \\
\hline Loyalty & Number of fans & Number of followers & Number of subscribers \\
\hline Efficiency & Click-through rate & Average amount of link clicks & Total watch time \\
\hline
\end{tabular}

Hospitals can compare their own results at different stages (last year, last month, etc.) or compare them with main and secondary competitors (Jeffrey, 2013). Once the Social Media Manager has access to both quantitative and qualitative data, they should understand and summarize these insights to justify some of the strategic decisions concerning the next annual corporate communication plan. These data are useful to update plans and protocols, and legitimize the Social Media Unit as a professional department able to improve the hospital's brand. In other words, the MedPac Model for Building Cancer Hospital Brands is a communication tool based on a management logic with the main objective of proving the importance of social media as the best corporate communication platform for building a reputable cancer hospital brand.

\section{Conclusion}

The use of social media by cancer hospitals constitutes a challenge as well as an opportunity. Hospitals, public authorities, patient associations, and universities should work together to establish useful guidelines that allow cancer hospitals to implement branding initiatives in a responsible and efficient way. While this literature review paper highlights several important insights in this domain, we also identify some limitations, such as the lack of quantitative data on how hospitals use social media platforms, the absence of academic references for authors working outside the USA and Spain, and the lack of references for the annual reports published by public authorities. Despite these limitations, this paper is useful to help cancer hospitals and academic researchers update their practices and knowledge, and revisit their professional practices related to social media platforms.

Managing social media as a corporate communication tool allows hospitals to improve relationships with stakeholders. Thanks to these platforms, these organizations can satisfy stakeholder needs in terms of informational and emotional support. Nevertheless, cancer hospitals also face several problems such as the lack of privacy, the difficulty in disseminating scientific content, stakeholder needs, and legal issues. After analyzing what the main experts in health communication think about cancer hospitals, social media, and reputation, we consider the MedPac Model for Building Cancer Hospital Brands to be an efficient proposal for the integration of social media practices into cancer hospitals and the improvement of stakeholders' perceptions. Three reasons lead us to the following conclusions: First, this model prioritizes people, not companies: brand ambassadors (doctors, nurses, social workers, etc.) are more credible than corporate departments (communication, public relations, etc.), not only because people prefer to interact with other people rather than corporate structures, but also because brand ambassadors are credible sources of information from a scientific point of view. Second, this model focuses on scientific and emotional content, rather than business information: disseminating insights that are useful to stakeholders (diseases, treatments, etc.) constitutes an opportunity to build new relationships with them. This altruistic approach is useful not only for stakeholders but also for hospital brands. And third, this model focuses on human values such as patient integrity, ethics, freedom of information, social responsibility, and social education: it is thanks to these values that patients can feel more empowered and hospitals can become meaningful brands with the ability to help people enhance their quality of life.

\section{Notes}

1. According to SCImago Journal and Country Rank (2019), in "Health Social Science," six out of the ten "best" journals are published in the USA. $h$ ttps://www.scimagojr.com/journalrank.php?area=3300\&category=3306

The journals with the best reputation (SJR index) specialized in health communication are published in the USA and ranked in Scopus: Journal of health communication (New York); Journal of communication in healthcare (New York); and Health communication (Ohio).

2. In Spain there are two scientific journals in this domain: Revista Española de Comunicación en Salud (Universidad Carlos III), and Revista de Comunicación y Salud (Universidad Complutense de Madrid). Many universities offer masters 
programs focused on this domain, e.g., Escuela Andaluza de Salud Pública, Universitat Pompeu Fabra, Universidad Carlos III de Madrid, and Universidad de Valencia.

\section{References}

Anisimova, Tatiana (2013). "Evaluating the impact of corporate brand on consumer satisfaction". Asia Pacific journal of marketing and logistics, v. 25, n. 4, pp. 561-589.

https://doi.org/10.1108/APJML-12-2012-0132

Antheunis, Marjolijn L.; Tates, Kiek; Nieboer, Theodoor E. (2013). “Patients' and health professionals' use of social media in healthcare: motives, barriers and expectations". Patient education and counselling, v. 92, n. 3, pp. $426-431$. https://doi.org/10.1016/j.pec.2013.06.020

Apenteng, Bettye A.; Ekpo, Imaobong B.; Mutiso, Fedelis M.; Akowuah, Emmanuel A.; Opoku, Samuel T. (2020). “Examining the relationship between social media engagement and hospital revenue". Health marketing quarterly, v. 25, pp. $1-12$.

https://doi.org/10.1080/07359683.2020.1713575

Attai, Deanna J.; Sedrak, Mina S.; Katz, Matthew S.; Thompson, Michael A.; Anderson, Patricia F.; Kesselheim, Jennifer C.; Fisch, Michael J.; Graham, David L.; Utengen, Audun; Johnston, Claire; Miller, Robert S.; Dizon, Don S.; COSMO (2016). "Social media in cancer care: highlights, challenges \& opportunities". Future oncology, v. 12, n. 13, pp. $1549-1552$. https://doi.org/10.2217/fon-2016-0065

Badr, Hoda (2017). "New frontiers in couple-based interventions in cancer care: refining the prescription for spousal communication". Acta oncologica, v. 56, n. 2, pp. 139-145.

https://doi.org/10.1080/0284186X.2016.1266079

Badr, Hoda; Carmack, Cindy L.; Diefenbach, Michael A. (2015). "Psychosocial interventions for patients and caregivers in the age of new communication technologies: Opportunities and challenges in cancer care". Journal of health communication, v. 20, n. 3, pp. 328-342.

https://doi.org/10.1080/10810730.2014.965369

Balasooriya-Smeekens, Chantal; Walter, Fiona M.; Scott, Suzanne (2015). "The role of emotions in time to presentation for symptoms suggestive of cancer: a systematic literature review of quantitative studies". Psychooncology, v. 24, n. 12, pp. 1594-1604.

https://doi.org/10.1002/pon.3833

Bardach, Naomi S.; Asteria-Peñaloza, Renée; Boscardin, W. John; Dudley, R. Adams (2013). "The relationship between commercial website ratings and traditional hospital performance measures in the USA". BMJ quality \& safety, v. $22, \mathrm{n}$. 3, pp. 194-202.

https://doi.org/10.1136/bmjqs-2012-001360

Basch, Corey H.; Basch, Charles E.; Hillyer, Grace-Clarke; Reeves, Rachel (2015). "YouTube videos related to skin cancer: A missed opportunity for cancer prevention and control". JMIR cancer, v. 2, n. 1, e1.

https://doi.org/10.2196/cancer.4204

Becerra-Muñoz, Elena; Reina-Estévez, Jesús; Victoria-Mas, Juan-Salvador (2015). “Comunicación e imagen de los servicios sanitarios. El caso de los centros hospitalarios andaluces (2004-2013)". Prisma social. Revista de ciencias sociales, n. 14, 28 pp.

https://www.redalyc.org/pdf/3537/353744530001.pdf

Beesley, Helen; Goodfellow, Sarah; Hocombe, Christopher; Salmon, Peter (2016). "The intensity of breast cancer patients' relationships with their surgeons after the first meeting: Evidence that relationships are not 'built' but arise from attachment processes". European journal of surgical oncology, v. 42, n. 5, pp. 679-684.

https://doi.org/10.1016/j.ejso.2016.02.001

Bermúdez-Tamayo, Clara; Alba-Ruiz, Rubén; Jiménez-Pernett, Jaime; García-Gutiérrez, José-Francisco; Traver-Salcedo, Vicente; Yubraham-Sánchez, David (2013). "Use of social media by Spanish hospitals: Perceptions, difficulties, and success factors". Telemedicine and e-health, v. 19, n. 2, pp. 137-145.

https://doi.org/10.1089/tmj.2012.0066

Blanch-Hartigan, Danielle; Chawla, Neetu; Moser, Richard; Finney-Rutten, Lila; Hesse, Bradford; Arora, Neeraj (2016). "Trends in cancer survivors' experience of patient-centered communication: results from the Health Information National Trends Survey (HINTS)". Journal of cancer survivorship, v. 10, n. 6, pp. 1067-1077.

https://doi.org/10.1007/s11764-016-0550-7

Blomgren, Maria; Hedmo, Tina; Waks, Caroline (2016). “Being special in an ordinary way: Swedish hospitals' strategic web communication". International journal of strategic communication, v. 10, n. 3, pp. 177-194.

https://doi.org/10.1080/1553118X.2016.1176569 
Boudewyns, Vanessa; Himelboim, Itai; Hansen, Derek (2015). "Stigma's effect on social interaction and social media activity". Journal of health communication, v. 20, n. 11, pp. 1337-1345.

https://doi.org/10.1080/10810730.2015.1018604

Brent, Ruben (2016). "Communication theory and health communication practice: The more things change, the more they stay the same". Health communication, v. 31, n. 1, pp. 1-11.

https://doi.org/10.1080/10410236.2014.923086

Bubien, Yves (2015). "Hôpital 2.0: du virtuel au réel”. European psychiatry, v. 30, n. 8, S74.

Burleson, Debra (2014). "Communication challenges in the hospital setting: A comparative case study of hospitalists and patients' perception". Journal of business and technical communication, v. 28, n. 2, pp. 187-221. https://doi.org/10.1177/1050651913513901

Cady, Steven H.; Wheeler, Jane V.; DeWolf, Jeff; Brodke, Michelle (2011). "Mission, vision and values: what do they say?". Organizational development journal, v. 29, n. 1, pp. 63-78.

https://scholarworks.bgsu.edu/management_pub/19

Campbell, Brittany C.; Craig, Clay M. (2014). "Social media and health: current and future healthcare provider perspectives". Journal of contemporary medical education, v. 2, n. 2, pp. 128-133.

https://www.jcmedu.org/jcmedu-articles/social-media-and-health-current-and-future-healthcare-provider-perspectives.pdf

Cho, Hyunyi; Silver, Nathan; Na, Kilhoe; Adams, Dinah; Luong, Kate; Song, Chi (2018). "Visual cancer communication on social media: An examination of content and effects of \#Melanomasucks". Journal of medical internet research, v. 20, n. 9, e10501.

https://doi.org/10.2196/10501

Chou, Wen-Ying-Sylvia; Hunt, Yvonne; Folkers, Anna; Augustson, Erik (2011). "Cancer survivorship in the age of YouTube and social media: A narrative analysis". Journal of medical internet research, v. 13, n. 1, e7.

https://doi.org/10.2196/jmir.1569

Costa-Sánchez, Carmen; Míguez-González, María-Isabel (2018). “Use of social media for health education and corporate communication of hospitals". El profesional de la información, v. 27, n. 5, pp. 1145-1150.

https://doi.org/10.3145/epi.2018.sep.18

Cua, Santino; Moffatt-Bruce, Susan; White, Susan (2017). "Reputation and the best hospital rankings: What does it really mean?". American journal of medical quality, v. 32, n. 6, pp. 632-637.

https://doi.org/10.1177/1062860617691843

D’Agostino, Thomas; Bylund, Carma (2014). "Nonverbal accommodation in health care communication". Health communication, v. 29, n. 6, pp. 563-573.

https://doi.org/10.1080/10410236.2013.783773

Dean, Marleah; Oetzel, John (2014). "Physicians' perspectives of managing tensions around dimensions of effective communication in the emergency department". Health communication, v. 29, n. 3, pp. 257-266.

https://doi.org/10.1080/10410236.2012.743869

De-Benedictis, Anna; Lettieri, Emanuele; Masella, Cristina; Gastaldi, Luca; Macchini, Giordana; Santu, Camilla; Tartaglini, Daniela (2019). "WhatsApp in hospital? An empirical investigation of individual and organizational determinants to use". PLOS one, v. 14, n. 1, e0209873.

https://doi.org/10.1371/journal.pone.0209873

De-Las-Heras-Pedrosa, Carlos; Rando-Cueto, Dolores; Jambrino-Maldonado, Carmen; Paniagua-Rojano, Javier (2020). "Analysis and study of hospital communication via social media from the patient perspective". Cogent social sciences, v. 6, n. 1.

https://doi.org/10.1080/23311886.2020.1718578

De-Vries, Mirjam; Gholam, Mehdi; Verdonck, Leeuw; Roten, Yves (2018). "Physicians' emotion regulation during communication with advanced cancer patients". Psychooncology, v. 27, n. 3, pp. 929-936.

https://doi.org/10.1002/pon.4614

Dizon, Don S.; Graham, David; Thompson, Michael A.; Johnson, Lisa J.; Johnston, Claire; Fisch, Michael J.; Miller, Robert (2012). "Practical guidance: The use of social media in oncology practice". Journal of oncology practice, v. 8, n. 5, e114-e124.

https://doi.org/10.1200/JOP.2012.000610

Drake, Thomas M.; Claireaux, Henry A.; Khatri, Chetan; Chapman, Stephen J. (2016). "WhatsApp with patient data transmitted via instant messaging?" The American journal of surgery, v. 211, n. 1, pp. 300-301.

https://doi.org/10.1016/j.amjsurg.2015.04.004 
Epstein, Ronald; Duberstein, Paul; Fenton, Joshua (2017). "Effect of a patient-centered communication intervention on oncologist-patient communication, quality of life, and health care utilization in advanced cancer. The Voice randomized clinical trial". Jama oncology, v. 3, n. 1, pp. 92-100.

https://doi.org/10.1001/jamaoncol.2016.4373

Esposito, Annamaria (2017). "Hospital branding in Italy: A pilot study based on the case method". Health marketing quarterly, v. 34, n. 1, pp. 35-47.

https://doi.org/10.1080/07359683.2016.1275211

Falisi, Angela; Wiseman, Kara; Gaysynsky, Anna; Scheideler, Jennifer; Ramin, Danielle; Chou, Sylvia (2017). "Social media for breast cancer survivors: a literature review". Journal of cancer survivorship, v. 11, n. 6, pp. 808-821.

https://doi.org/10.1007/s11764-017-0620-5

Farnan, Jeanne; Snyder, Lois; Worster, Brooke; Chaudhry, Humayun; Rhyne, Janette; Arora, Vineet (2013). “Online medical professionalism: patient and public relationships: policy statement from the American College of Physicians and the Federation of State Medical Boards". Annals international of medicine, v. 158, n. 8, pp. 620-627.

https://doi.org/10.7326/0003-4819-158-8-201304160-00100

Fernández-Gómez, Erika; Díaz-Campo, Jesús (2016). “Comunicación sobre el cáncer en Facebook: Las asociaciones de Argentina, Chile, Colombia y España”. Cuadernos.info, v. 38, pp. 35-50.

https://doi.org/https://dx.doi.org/10.7764/cdi.38.926

Fernández-Luque, Luis; Bau, Teresa (2015). "Health and social media: perfect storm of information". Healthcare informatics research, v. 21, n. 2, pp. 67-73.

https://doi.org/10.4258/hir.2015.21.2.67

Fernández-Silano, Mariano (2013). "La Salud 2.0 y la atención de la salud en la era digital”. Revista médica de Risaralda, v. 20, n. 1, pp. 41-46.

https://revistas.utp.edu.co/index.php/revistamedica/article/view/8483

Fischer, Sophia (2014). "Hospital positioning and Integrated hospital marketing communications: State-of-the-art review, conceptual framework, and research agenda". Journal of nonprofit \& public sector marketing, v. 26, n. 1, pp. 1-34. https://doi.org/10.1080/10495142.2014.870431

Foufi, Vasiliki; Timakum, Tatsawan; Gaudet-Blavignac, Christophe; Lovis, Christian; Song, Ming (2019). "Mining of textual health information from Reddit: Analysis of chronic diseases with extracted entities and their relations". Journal of medical internet research, v. 21, n. 6, e12876.

https://doi.org/10.2196/12876

Freedman, Rachel A.; Viswanath, Kasisomayajula; Vaz-Luis, Ines; Keating, Nancy L. (2016). "Learning from social media: utilizing advanced data extraction techniques to understand barriers to breast cancer treatment". Breast cancer research and treatment, n. 158, pp. 395-405.

https://doi.org/10.1007/s10549-016-3872-2

Gage-Bouchard, Elizabeth A.; LaValley, Susan; Mollica, Michelle; Beaupin, Lynda-Kwon (2017). "Examinig how cancer caregivers use Facebook for cancer-related communication". Cancer nursing, v. 40, n. 4, pp. 332-338.

https://doi.org/10.1097/NCC.0000000000000418

Garga, Poonam; Gupta, Bhumika; Dzever, Sam; Sivarajahc, Uthayasankar; Kumar, Viskas (2020). "Examining the relationship between social media analytics practices and business performance in the Indian retail and IT industries: The mediation role of customer engagement". International journal of information management, v. 50, pp. 575-585.

https://doi.org/10.1016/j.ijinfomgt.2020.102069

Gay, Susan; Pho, Kevin (2013). "Online reputation management: The first steps". The journal of medical practice management, v. 29, n. 2, pp. 81-83.

https://www.physicianleaders.org/news/online-reputation-management-the-first-steps

Glover, McKinley; Khalilzadeh, Omid; Choy, Garry; Prabhakar, Anand; Pandharipande, Pari; Gazelle, Scott (2015). “Hospital evaluations by social media: A comparative analysis of Facebook ratings among performance outliers". Journal of general internal medicine, v. 30, n. 10, pp. 1440-1446.

https://doi.org/10.1007/s11606-015-3236-3

Grajales, Francisco-José; Sheps, Samuel; Kendall, Ho; Novak-Lauscher, Helen; Eysenbach, Gunther (2014). "Social media: A review and tutorial of applications in medicine and health care". Journal of medical internet research, v. 16, n. 2, e13. https://doi.org/10.2196/jmir.2912

Grant, Maria J.; Booth, Andrew (2009). "A typology of reviews: an analysis of 14 review types and associated methodologies". Health information and libraries journal, v. 26, pp. 91-108.

https://doi.org/10.1111/j.1471-1842.2009.00848.x 
Greaves, Felix; Ramírez-Cano, Daniel; Millett, Christopher; Darzi, Ara; Donaldson, Liam (2013). “Harnessing the cloud of patient experience: Using social media to detect poor quality healthcare". BMJ quality \& safety, v. 22, n. 3, pp. 251255.

https://doi.org/10.1136/bmjqs-2012-001527

Greysen, Ryan; Kind, Terry; Chretien, Katherine (2010). “Online professionalism and the mirror of social media”. Journal of general internal medicine, v. 25, n. 11, pp. 1227-1229.

https://doi.org/10.1007/s11606-010-1447-1

Griffis, Heather; Kilaru, Austin; Werner, Rachel; Asch, David; Hershey, John; Hill, Shawndra; Ha, Yoonhee; Sellers, Allison; Mahoney, Kevin; Merchant, Raiana (2014). "Use of social media across us hospitals: Descriptive analysis of adoption and utilization". Journal of medical internet research, v. 16, n. 11, e264.

https://doi.org/10.2196/jmir.3758

Gurau, Calin (2013). "Developing an environmental corporate reputation on the internet". Marketing intelligence \& planning, v. 31, n. 5, pp. 522-537.

https://doi.org/10.1108/MIP-04-2013-0059

Gurrieri, Lauren; Drenten, Jenna (2019). "Visual storytelling and vulnerable health care consumers: normalising practices and social support through Instagram". Journal of services marketing, v. 33, n. 6, pp. 702-720.

https://doi.org/10.1108/JSM-09-2018-0262

Haluza, Daniela; Naszay, Marlene; Stockinger, Andreas; Jungwirth, David (2016). "Digital natives versus digital immigrants: Influence of online health information seeking on the doctor-patient relationship". Health communication, v. 32 , n. 11 , pp. 1342-1349.

https://doi.org/10.1080/10410236.2016.1220044

Han, Jeong-Yeob; Hawkins, Robert; Baker, Timothy; Shah, Dhavan V.; Pingree, Suzanne; Gustafson, David H. (2017). "How cancer patients use and benefit from an interactive cancer communication system". Journal of health communication, v. 22, n. 10, pp. 792-799.

https://doi.org/10.1080/10810730.2017.1360413

Hannawa, Annegret F.; García-Jiménez, Leonarda; Candrian, Carey; Rossmann, Constanze; Schulz, Peter J. (2015). "Identifying the field of health communication". Journal of health communication, v. 20, n. 5, pp. 521-530.

https://doi.org/10.1080/10810730.2014.999891

He, Hong-Wei; Balmer, John (2013). "A grounded theory of the corporate identity and corporate strategy dynamic". European journal of marketing, v. 47, n. 3-4, pp. 401-430.

https://doi.org/10.1108/03090561311297391

Heide, Mats; Simonsson, Charlotte (2014). "Developing internal crisis communication new roles and practices of communication professionals". Corporate communications: An international journal, v. 19, n. 2, pp. 128-146.

https://doi.org/10.1108/CCIJ-09-2012-0063

Hendriks, Hanneke; Van-den-Putte, Bas; De-Bruijn, Gert-Jan; De-Vreese, Claes H. (2014). "Predicting health: The interplay between interpersonal communication and health campaigns". Journal of health communication, v. 19, n. 5, pp. 625-636.

https://doi.org/10.1080/10810730.2013.837552

Househ, Mowafa; Borycki, Elizabeth; Kushniruk, Andre (2014). “Empowering patients through social media: The benefits and challenges". Health informatics journal, v. 20, n. 1, pp. 50-58.

https://doi.org/10.1177/1460458213476969

Huang, Edgar (2013). "US hospitals on YouTube: a test to the altruistic marketing approach". Journal of communication in healthcare, v. 6, n. 2, pp. 128-134.

https://doi.org/10.1179/1753807613Y.0000000035

Huesch, Marco D.; Currid-Halkett, Elizabeth; Doctor, Jason N. (2014). "Public hospital quality report awareness: evidence from National and Californian Internet searches and social media mentions, 2012". BMJ open, v. 11, n. 4, e004417. https://doi.org/10.1136/bmjopen-2013-004417

International Association for the Measurement and Evaluation of Communication (2020). Barcelona Principles 3.0. https://amecorg.com/2020/07/barcelona-principles-3-0

Ivanov, Anton; Sharman, Raj (2018). "Impact of user-generated internet content on hospital reputational dynamics". Journal of management information systems, v. 35, n. 4, pp. 1277-1300.

https://doi.org/10.1080/07421222.2018.1523603 
Jahromi, Vahid; Tatabaee, Seyed; Abdar, Zahra; Rajabi, Mahboobeh (2016). "Active listening: The key of successful communication in hospital managers". Electronic physician, v. 8, n. 3, pp. 2123-2128.

https://doi.org/10.19082/2123

Jeffrey, Angela (2013). Social media measurement: A step-by-step approach using the AMEC valid metrics framework. London: Institute for Public Relations, June 6.

https://instituteforpr.org/social-media-measurement-a-step-by-step-approach

Jeong, Michelle; Tan, Andy S. L.; Brennan, Emily; Gibson, Laura; Hornik, Robert C. (2015). "Talking about quitting: Interpersonal communication as a mediator of campaign effects on smokers' quit behaviors". Journal of health communication, v. 20, n. 10, pp. 1196-1205.

https://doi.org/10.1080/10810730.2015.1018620

Johnson, Katie (2014). "The link between patient experience and hospital reputation". National research corporation, February, pp. 1-8.

https://nrchealth.com/wp-content/uploads/2016/11/Link-Between-Patient-Experience-and-Hospital-Reputation.pdf

Jones, Christina L.; Jensen, Jakob D.; Scherr, Courtney L.; Brown, Natasha R.; Christy, Katheryn; Weaver, Jeremy (2015). "The health belief model as an explanatory framework in communication research: Exploring parallel, serial, and moderated mediation". Health communication, v. 30, n. 6, pp. 566-576.

https://doi.org/10.1080/10410236.2013.873363

Kamel-Boulos, Maged N.; Giustini, Dean M.; Wheeler, Steve (2016). "Instagram and WhatsApp in health and healthcare: An overview". Future internet, v. 8, n. 3, e37.

https://doi.org/10.3390/fi8030037

Keim, Madelaine C.; Lehmann, Vicky; Shultz, Emily L.; Winning, Adrien M.; Rausch, Joseph R.; Barrera, Maru; Gilmer, Mary Jo; Murphy, Lexa K.; Vannatta, Kathryn A.; Compas, Bruce E.; Gerhardt, Cynthia A. (2017). "Parent-child communication and adjustment among children with advanced and non-advanced cancer in the first year following diagnosis or relapse". Journal of pediatric psychology, v. 42, n. 8, pp. 871-881.

https://doi.org/10.1093/jpepsy/jsx058

Kemp, Elyria; Jillapalli, Ravi; Becerra, Enrique (2014). “Healthcare branding: developing emotionally based consumer brand relationships". Journal of services marketing, v. 28, n. 2, pp. 126-137.

https://doi.org/10.1108/JSM-08-2012-0157

Kim, Eunkyung; Hou, Jiran; Han, Jeong; Himelboim, Itai (2016). “Predicting retweeting behavior on breast cancer social networks: Network and content characteristics". Journal of health communication, v. 21, n. 4, pp. 479-486.

https://doi.org/10.1080/10810730.2015.1103326

Klabunde, Chris N.; Haggstrom, Dan; Kahn, Katherine L.; Gray, Stacy W.; Kim, Benjamin; Liu, B; Eisenstein, J. C.; Keating, Nancy L. (2017). “Oncologists' perspectives on post-cancer treatment communication and care coordination with primary care physicians". European journal of cancer care, v. 26, n. 4.

https://doi.org/10.1111/ecc.12628

Kotsenas, Amy L.; Aase, Lee; Arce, Makala; Timimi, Farris K.; Dacy, Matthew; Young, Colleen; Wald, John T. (2018). “The social media DNA of Mayo Clinic - and health care". Journal of American College of Radiology, v. 15, n. 1, pp. $162-166$. https://doi.org/10.1016/j.jacr.2017.09.026

Kumar, P. Naveen; Jacob, Anil; Thota, Smruthi (2014). "Impact of healthcare marketing and branding on hospital services". International journal of research foundation of hospital \& healthcare administration, v. 2, n. 1, pp. 19-24.

https://doi.org/10.5005/jp-journals-10035-1010

Kwateng, Kwame-Owusu; Osei, Hannah-Vivian; EkowAbban, Ernest (2014). "Organizational communication in public health institutions". International journal of business and management, v. 9, n. 11, pp. 179-188.

https://doi.org/10.5539/ijbm.v9n11p179

Lagu, Tara; Goff, Sarah L.; Craft, Ben; Calcasola, Stephanie; Benjamin, Evan M.; Priya, Aruna; Lindenauer, Peter K. (2016). "Can social media be used as a hospital quality improvement tool?". Journal of hospital medicine, v. 11, n. 1, pp. 52-55.

https://doi.org/10.1002/jhm.2486

Langer, Shelby; Romano, Joan M.; Todd, Michael; Strauman, Timothy J.; Keefe, Francis J.: Syrjala, Karen L.; Bricker, Jonathan B.; Ghosh, Neeta; Burns, John W.; Bolger, Niall; Puleo, Blair K.; Gralow, Julie R.; Shankaran, Veena; Westbrook, Kelly; Zafar, S. Yousuf; Porter, Laura S. (2018). "Links between communication and relationship satisfaction among patients with cancer and their spouses: Results of a fourteen-day smartphone-based ecological momentary assessment study". Frontiers psychology, v. 10, n. 9, pp. 1843.

https://doi.org/10.3389/fpsyg.2018.01843 
Laroche, Michel; Habibi, Mohammad-Reza; Richard, Marie-Odile (2013). "To be or not to be in social media: How brand loyalty is affected by social media?". International journal of information management, v. 33, n. 1, pp. 76-82.

https://doi.org/10.1016/j.ijinfomgt.2012.07.003

Lee, Joy L.; Choudhry, Niteesh K.; Wu, Albert W.; Matlin, Olga S.; Brennan, Troyen A.; Shrank, William H. (2015). "Patient use of email, Facebook, and physician websites to communicate with physicians: A national online survey of retail pharmacy users". Journal of general internal medicine, v. 31, pp. 45-51.

https://doi.org/10.1007/s11606-015-3374-7

Lim, Weng-Marc (2016). "Social media in medical and health care: opportunities and challenges". Marketing intelligence \& planning, v. 34, n. 7, pp. 964-976. https://doi.org/10.1108/MIP-06-2015-0120

López-Bolás, Alba; Valderrama-Santomé, Monica; Di-Virgilio, Francesca (2019). “Claves del éxito para la viralización de contenidos de salud. El caso de las redes sociales del Hospital Povisa". El profesional de la información, v. 28, n. 5. https://doi.org/10.3145/epi.2019.sep.02

Maier, Craig T. (2016). "Beyond branding: Van Riel and Fombrun's corporate communication theory in the human services sector". Qualitative research reports in communication, v. 17, n 1, pp. 27-35. https://doi.org/10.1080/17459435.2015.1088892

Marca-Francés, Guillem; Frigola-Reig, Joan; Compte-Pujol, Marc (2019). “Análisis de la comunicación en el paciente crónico hospitalizado y la mejora de su experiencia". El profesional de la información, v. 28, n. 2.

https://doi.org/10.3145/epi.2019.mar.21

Matarín-Jiménez, Tamara M. (2015). “Redes sociales en prevención y promoción de la salud. Una revisión de la actualidad". Revista española de comunicación de salud, v. 6, n. 1, pp. 62-69.

https://e-revistas.uc3m.es/index.php/RECS/article/view/3328

Mazor, Kathleen M.; Street, Richard L.; Sue, Valerie M.; Williams, Andrew E.; Rabin, Borsika A.; Arora, Neeraj K. (2016). "Assessing patients' experiences with communication across the cancer care continuum". Patient education and counseling, v. 99, n. 8, pp. 1343-1348.

https://doi.org/10.1016/j.pec.2016.03.004

McCarroll, Michele L.; Armbruster, Shannon D.; Chung, Jae-Eun; Kim, Junghyun; McKenzie, Alissa; Von-Gruenigen, Vivian E. (2014). "Health care and social media platforms in hospitals". Health communication, v. 29, n. 9, pp. $947-952$. https://doi.org/10.1080/10410236.2013.813831

McKeever, Brook-Weberling (2014). "The status of health communication: Education and employment outlook for a growing field". Journal of health communication, v. 19, n. 12, pp. 1408-1423.

https://doi.org/10.1080/10810730.2014.904024

Medina-Aguerrebere, Pablo (2018a). “'Limpact des réseaux sociaux sur la gestion professionnelle de la communication hospitalière au Royaume-Uni». Observatorio. Obs* journal, v. 11, n. 4, pp. 13-25.

https://doi.org/10.15847/obsOBS12420181125

Medina-Aguerrebere, Pablo (2018b). "Le rôle des réseaux sociaux dans la communication de marque des hopitaux canadiens». Revue canadienne des sciences de l'information et de bibliothéconomie, v. 42, n. 3-4, pp. 176-191.

https://muse.jhu.edu/article/743051

Medina-Aguerrebere, Pablo; González-Pacanowski, Toni; Medina, Eva (2020). "The impact of social media in building hospital brands based on human values: a proposal model". Ponte: Multidisciplinary journal of sciences and research, $\mathrm{v}$. 76, n. 2, pp. 107-118. https://doi.org/10.21506/j.ponte.2020.2.9

Míguez-González, María-Isabel; García-Crespo, Oswaldo; Ramahí-García, Diana (2019). “Análisis de vídeos sobre cáncer de mama en YouTube". Cuadernos.info, v. 44, pp. 179-193.

https://doi.org/10.7764/cdi.44.1528

Miller, Carrie A.; Guidry, Jeanine P. D.; Fuemmeler, Bernard F. (2019). "Breast cancer voices on Pinterest: Raising awareness or just an inspirational image?" Health education and behaviour, v. 46, n. 2S, pp. 49S-58S. https://doi.org/10.1177/1090198119863774

Miller, Amalia R.; Tucker, Catherine E. (2013). "Active social media management: the case of health care". Information systems research, v. 24, n. 1, pp. 52-70. https://doi.org/10.2139/ssrn.1984973 
Mira, José-Joaquín; Lorenzo, Susana; Navarro, Isabel (2014). "Hospital reputation and perceptions of patient safety". Medical principles and practice, v. 23, pp. 92-94.

https://doi.org/10.1159/000353152

Moore, Philippa M.; Rivera, Solange; Bravo-Soto, Gonzalo A.; Olivares, Camila; Lawrie, Theresa A. (2018). "Communication skills training for healthcare professionals working with people who have cancer". Cochrane database system review, v. 24, n. 7, CD003751.

https://doi.org/10.1002/14651858.CD003751.pub4

Moorhead, S. Anne; Hazlett, Diane E.; Harrison, Laura; Carroll, Jennifer K.; Irwin, Anthea; Hoving, Ciska (2013). “A new dimension of health care: Systematic review of the uses, benefits, and limitations of social media for health communication". Journal of medical internet research, v. 15, n. 4, e85.

https://doi.org/10.2196/jmir.1933

Moran, Meghan-Bridgid; Sussman, Steve (2014). "Translating the link between social identity and health behavior into effective health communication strategies: An experimental application using antismoking advertisements". Health communication, v. 29, n. 10, pp. 1057-1066.

https://doi.org/10.1080/10410236.2013.832830

Moreno, Ángeles; Wiesenberg, Markus; Verčič, Dejan (2016). “Excelencia en la gestión de comunicación. Análisis de los departamentos de comunicación en España mediante el comparative excellence framework". Comhumanitas: Revista científica de comunicación, v. 7, n. 2.

http://www.comhumanitas.org/index.php/comhumanitas/article/view/Moreno

Moser, H. Ronald; Freeman, Gordon L. (2014). “An empirical analysis of the public's attitudes toward advertising hospital services: A comparative cross-sectional study". Health marketing quarterly, v. 31, pp. 13-30.

https://doi.org/10.1080/07359683.2013.847334

Mosquera, Margarita; Meléndez, Victoria; Latasa, Pello (2015). “Handling Europe's first Ebola case: internal hospital communication experience". American journal of infection control, v. 43, n. 4, pp. 386-389.

https://doi.org/10.1016/j.ajic.2015.01.015

Myrick, Jessica-Gall; Holton, Avery E.; Himelboim, Itai; Love, Brad (2016). “\#Stupidcancer: Exploring a typology of social support and the role of emotional expression in a social media community". Health communication, v. 31, n. 5, pp. 596-605.

https://doi.org/10.1080/10410236.2014.981664

Namkoong, Kang; Nah, Seungahn; Record, Rachael A.; Van-Stee, Stephanie K. (2017). "Communication, reasoning, and planned behaviors: Unveiling the effect of interactive communication in an anti-smoking social media campaign". Health communication, v. 32, n. 1, pp. 41-50.

https://doi.org/10.1080/10410236.2015.1099501

Nazione, Samantha; Pace, Kristin; Russell, Jessica; Silk, Kami (2013). "A 10year content analysis of original research articles published in health communication and journal of health communication (2000-2009)". Journal of health communication, v. 18, n. 2, pp. 223-240.

https://doi.org/10.1080/10810730.2012.688253

Nelson, William A.; Taylor, Emily; Walsh, Thom (2014). "Building an ethical organizational culture". The health care manager, v. 33, n. 2, pp. 158-164.

https://doi.org/10.1097/HCM.0000000000000008

Noar, Seth M.; Leas, Eric; Althouse, Benjamin M.; Dredze, Mark; Kelley, Danielle; Ayers, John W. (2018). “Can a selfie promote public engagement with skin cancer?". Preventive medicine, v. 111, pp. 280-283.

https://doi.org/10.1016/j.ypmed.2017.10.038

Oberlo (2020). Most popular social media platforms in 2020.

https://www.oberlo.com/statistics/most-popular-social-media-platforms

Ortega-Parra, Antonio; Sastre-Castillo, Miguel-Ángel (2013). "Impact of perceived corporate culture on organizational commitment". Management decision, v. 51, n. 5, pp. 1071-1083.

https://doi.org/10.1108/MD-08-2012-0599

Park, Hyojung; Reber, Bryan H.; Chon, Myoung-Gi (2016). "Tweeting as health communication: Health organizations' use of Twitter for health promotion and public engagement". Journal of health communication, v. 21, n. 2, pp. 188-198. https://doi.org/10.1080/10810730.2015.1058435

Park, Hyojung; Rodgers, Shelly; Stemmle, Jon (2013). “Analyzing health organizations' use of Twitter for promoting health literacy". Journal of health communication, v. 18, n. 4, pp. 410-425.

https://doi.org/10.1080/10810730.2012.727956 
Paternotte, Emma; Van-Dulmen, Sandra; Van-der-Lee, Nadine; Scherpbier, Albert J. J. A.; Scheele, Fedde (2014). “Factors influencing intercultural doctor patient communication: a realist review". Patient education and counselling, v. 98, n. 4, pp. 420-445.

https://doi.org/10.1016/j.pec.2014.11.018

Pelitti, Pamela (2016). "Estrategias de comunicación interna y externa de los hospitales públicos bonaerenses de la Región Sanitaria X". Question. Revista especializada en comunicación y periodismo, v. 49, n. 1, pp. 368-379.

https://perio.un/p.edu.ar/ojs/index.php/question/article/view/3010

Peluchette, Joy V.; Karl, Katherine A.; Coustasse, Alberto (2016). "Physicians, patients, and Facebook: Could you? Would you? Should you?". Health marketing quarterly, v. 33, n. 2, pp. 112-126.

https://doi.org/10.1080/07359683.2016.1166811

Peterson, Emily B.; Ostroff, Jamie S.; DuHamel, Katherine N.; D’Agostino, Thomas A.; Hernández, Marisol; Canzona, Mollie R.; Bylund, Carma L. (2016). "Impact of provider-patient communication on cancer screening adherence: A systematic review". Preventive medicine, v. 93, pp. 96-105.

https://doi.org/10.1016/j.ypmed.2016.09.034

Pinho, José-Carlos; Rodrigues, Ana-Paula; Dibb, Sally (2014). "The role of corporate culture, market orientation and organizational commitment in organizational performance”. Journal of management development, v. 33, n. 4, pp. 374-398. https://doi.org/10.1108/JMD-03-2013-0036

Prochaska, Judith J.; Coughlin, Steven S.; Lyons, Elizabeth J. (2017). "Social media and mobile technology for cancer prevention and treatment". American Society of Clinical Oncology educational book, v. 37, pp. 128-137.

https://doi.org/10.14694/EDBK_173841

Rando-Cueto, Dolores; De-las-Heras-Pedrosa, Carlos (2016). “Análisis de la comunicación corporativa de los hospitales andaluces vía Twitter". Opción, v. 32, n. 8, pp. 557-576.

https://www.produccioncientificaluz.org/index.php/opcion/article/view/21552

Richter, Jason P.; Muhlestein, David B.; Wilks, Chrisanne E. A.; Hino, Raymond T. (2014). "Social media: how hospitals use it, and opportunities for futureuse". Journal of healthcare management, v. 59, n. 6, pp. 447-460.

https://doi.org/10.2196/jmir.3758

Robinson, Maren N.; Tansil, Kristin A.; Elder, Randy W.; Soler, Robin E.; Labre, Magdala P.; Mercer, Shawna L.; Eroglu, Dogan; Baur, Cynthia; Lyon-Daniel, Katherine; Fridinger, Fred; Sokler, Lynn A.; Green, Lawrence W.; Miller, Therese; Dearing, James W.; Evans, William D.; Snyder, Leslie B.; Viswanath, K. Kasisomayajula; Beistle, Diane M.; Chervin, Doryn D.; Bernhardt, Jay M.; Rimer, Barbara K.; Community Preventive Services Task Force (2014). "Mass media health communication campaigns combined with health-related product distribution: a community guide systematic review". American journal of preventive medicine, v. 47, n. 3, pp. 360-371.

https://doi.org/10.1016/j.amepre.2014.05.034

Rodrigues, Alexandra; Azevedo, Carlos; Calvo, Vítor (2016). "Internal communication in organizations: Practical instruments to help the shift change". Millenium, v. 2, n. 1, pp. 105-114.

https://doi.org/10.29352/mill0201.09.00004

Ruiz-Granja, María-José (2015). “Análisis comunicacional de páginas web hospitalarias. El caso de los hospitales sevillanos". Revista española de comunicación y salud, v. 6, n. 2, pp. 138-56.

https://e-revistas.uc3m.es/index.php/RECS/article/view/2934

Rupert, Douglas J.; Moultrie, Rebecca R.; Read, Jennifer-Gard; Amoozegar, Jacqueline B.; Bornkessel, Alexandra S.; O'Donoghue, Amie C.; Sullivan, Helen W. (2014). "Perceived healthcare provider reactions to patient and caregiver use of online health communities". Patient education and counseling, v. 96, n. 3, pp. 320-326.

https://doi.org/10.1016/j.pec.2014.05.015x

Salathé, Marcel; Freifeld, Clark C.; Mekaru, Sumiko R.; Tomasulo, Anna F.; Brownstein, John S. (2013). "Influenza A (H7N9) and the importance of digital epidemiology". The New England journal of medicine, v. 369, pp. 401-404. https://doi.org/10.1056/NEJMp1307752

Salmon, Peter; Bridget, Young (2017). "A new paradigm for clinical communication: critical review of literature in cancer care". Medical education, v. 51, pp. 258-268.

https://doi.org/10.1111/medu.13204

https://www.ncbi.nlm.nih.gov/pmc/articles/PMC5324633/

Sedrak, Mina S.; Dizon, Don S.; Anderson, Patricia F.; Fisch, Michael J.; Graham, David L.; Katz, Matthew S.; Kesselheim, Jennifer C.; Miller, Robert S.; Thompson, Michael A.; Utengen, Audun; Attai, Deanna J.; COSMO (2017). "The emerging role of professional social media use in oncology". Future oncology, v. 13, n. 15, pp. 1281-1285.

https://doi.org/10.2217/fon-2017-0161 
Seltzer, Trent; Gardner, Elizabeth; Bichard, Shannon; Callison, Coy (2012). "WPR in the ER: Managing internal organization-public relationships in a hospital emergency department". Public relations review, v. 38, n. 1, pp. 128-136. https://doi.org/10.1016/j.pubrev.2011.12.002

Seo, Mihye; Matsaganis, Matthew D. (2013). "How interpersonal communication mediates the relationship of multichannel communication connections to health enhancing and health-threatening behaviors". Journal of health communication, v. 18 , n. 8, pp. 1002-1020.

https://doi.org/10.1080/10810730.2013.768726

Sheehan, Norman; Isaac, Grant (2014). "Principles operationalize corporate values so they matter". Strategy \& leadership, v. 42, n. 3, pp. 23-30.

https://doi.org/10.1108/SL-03-2014-0021

Shipley, Nancy; Chakraborty, Joyram (2019). "Big data and mHealth: Increasing the usability of healthcare through the customization of Pinterest - Literary perspective". In: Khosrow-Pour (ed.). Consumer-driven technologies in healthcare: breakthroughs in research and practice, pp. 34-54. Hershey: IGI Global. ISBN: 9781522561989

Singal, Ajay; Jain, Arun (2013). "An empirical examination of the influence of corporate vision on internationalization". Strategic change, v. 22, n. 5-6, pp. 243-257.

https://doi.org/10.1002/jsc.1937

Smailhodzic, Edin; Hooijsma, Wyanda; Boonstra, Albert; Langley, David J. (2016). "Social media use in healthcare: A systematic review of effects on patients and on their relationship with healthcare professionals". BMC health services research, v. 16, 442. https://doi.org/10.1186/s12913-016-1691-0

Smith, Katherine-Taken (2017). "Hospital marketing and communications via social media". Services marketing quarterly, v. 38, n. 3, pp. 187-201.

https://doi.org/10.1080/15332969.2017.1363518

Sugawara, Yuya; Narimatsu, Hiroto; Hozawa, Atsushi; Shao, Li; Otani, Katsumi; Fukao, Akira (2012). "Cancer patients on Twitter: a novel patient community on social media". BMC res notes, n. 5, art. 699.

https://doi.org/10.1186/1756-0500-5-699

Sutton, Jeannette; Vos, Sarah C.; Olson, Michele K.; Woods, Chelsea; Cohen, Elisia; Gibson, C. Ben; Phillips, Nolan-Edward; Studts, Jamie L.; Eberth, Jan M.; Butts, Carter T. (2018). "Lung cancer messages on Twitter: Content analysis and evaluation". Journal of the American College of Radiology, v. 15, n. 1, pp. 210-217.

https://doi.org/10.1016/j.jacr.2017.09.043

Trepanier, Sylvain; Gooch, Pidge (2014). "Personal branding and nurse leader professional image". Nurse leader, v. 12, n. 3, pp. 51-57.

https://doi.org/10.1016/j.mnl.2014.03.005

Triemstra, Justin D.; Poeppelman, Rachel-Stork; Arora, Vineet M. (2018). “Correlations between hospitals' social media presence and reputation score and ranking: Cross-sectional analysis". Journal of medical internet research, v. 20, n. 11, e289. https://doi.org/10.2196/jmir.9713

Tsimonis, Georgios; Dimitriadis, Sergios (2014). "Brand strategies in social media". Marketing intelligence \& planning, v. 32, n. 3, pp. 328-344.

https://doi.org/10.1108/MIP-04-2013-0056

Veltri, Stefania; Nardo, Maria-Teresa (2013). "The intangible global report: an integrated corporate communication framework". Corporate communications: An international journal, v. 18, n. 1, pp. 26-51.

https://doi.org/10.1108/13563281311294119

Visser, Laura M.; Bleijenbergh, Inge L.; Benschop, Yvonne W. M.; Van-Riel, Allard C. R.; Bloem, Bastiaan R. (2016). “Do online communities change power processes in healthcare? Using case studies to examine the use of online health communities by patients with Parkinson's disease". British medical journal, v. 6, n. 11, e012110.

https://doi.org/10.1136/bmjopen-2016-012110

Vraga, Emily K.; Stefanidis, Anthony; Lamprianidis, Georgios; Croitoru, Arie; Crooks, Andrew T.; Delamater, Paul L.; Pfoser, Dieter; Radzikowski, Jacek R.; Jacobsen, Kathryn H. (2018). "Cancer and social media: A comparison of traffic about breast cancer, prostate cancer, and other reproductive cancers on Twitter and Instagram". Journal of health communication, v. 23, n. 2, pp. 181-189. https://doi.org/10.1080/10810730.2017.1421730

Wæraas, Arild; Byrkjeflot, Haldor (2012). "Public sector organizations and reputation management: Five problems". International public management journal, v. 15, n. 2, pp. 186-206.

https://doi.org/10.1080/10967494.2012.702590 
Wang, Yu-Che; Hsu, Kuei-Chu; Hsu, Sheng-Hsun; Hsieh, Po-An J. J. (2011). "Constructing an index for brand equity: a hospital example". The service industries journal, v. 31, n. 2, pp. 311-322.

https://doi.org/10.1080/02642060902759145

Weech-Maldonado, Robert; Elliott, Marc; Pradhan, Rohit; Schiller, Cameron; Hall, Allyson; Hays, Ron D. (2012). "Can hospital cultural competency reduce disparities in patient experiences with care". Medical care, v. 50, pp. S48-S55. https://doi.org/10.1097/MLR.0b013e3182610ad1

Whiteley, Alma; Price, Christine; Palmer, Rod (2013). “Corporate culture change: adaptive culture structuration and negotiated practice". Journal of workplace learning, v. 25, n. 7, pp. 476-498.

https://doi.org/10.1108/JWL-09-2012-0069

Wu, Chao-Chan (2011). "The impact of hospital brand image on service quality, patient satisfaction and loyalty". African journal of business management, v. 5, n. 12, pp. 4873-4882.

https://doi.org/10.5897/AJBM10.1347

Xie, Shuyan; Helfert, Markus; Lugmayr, Artur; Heimgärtner, Rüdiger; Holzinger, Andreas (2013). "Influence of organizational culture and communication on the successful implementation of information technology in hospitals". $5^{\text {th }}$ International conference, CCD 2013, Held as part of HCl International 2013, Las Vegas, NV, USA, July 21-26, 2013, Proceedings, Part II, pp. 165-174.

https://doi.org/10.1007/978-3-642-39137-8

Yang, Po-Chin; Lee, Wui-Chiang; Liu, Hao-Yen; Shih, Mei-Ju; Chen, Tzeng-Ji; Chou, Li-Fang; Hwang, Shinn-Jang (2018). "Use of Facebook by hospitals in Taiwan: A nationwide survey". International journal of environmental research and public health, v. 15, n. 6, 1188 .

https://doi.org/10.3390/ijerph15061188

Zerfass, Ansgar; Viertmann, Christine (2017). "Creating business value through corporate communication: A theory-based framework and its practical application". Journal of communication management, v. 21, n. 1, pp. 68-81. https://doi.org/10.1108/JCOM-07-2016-0059

Zhu, Chengyan; Xu, Xiaolin; Zhang, Wei; Chen, Jianmin; Evans, Richard (2020). "How health communication via Tik Tok makes a difference: A content analysis of Tik Tok accounts run by Chinese provincial health committees". International journal of environmental research and public health, v. 17, n. 1, 192.

https://doi.org/10.3390/ijerph17010192

\section{Inforảrea}

Ayudamos a tu organización en la transformación digital y el gobierno de la información

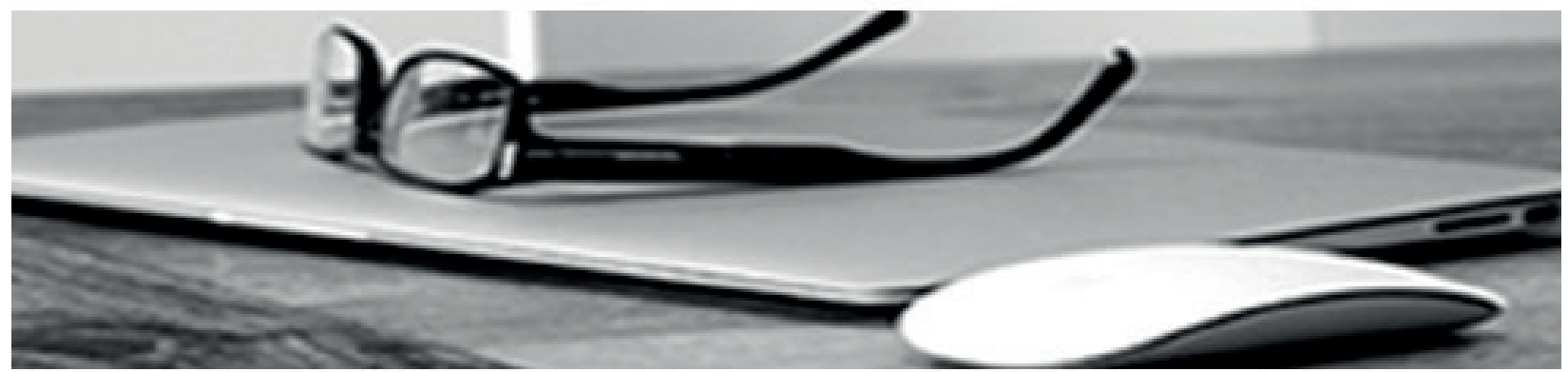

* Consultoría estratégica en gestión y gobierno de la información

* Gestión documental y "records management"

* Gestión de contenidos, intranets corporativas y entornos de colaboración

* Estudios especializados

Clientes satisfechos, cientos de empresas nacionales e internacionales y más de 30 años de experiencia son la mejor garantía de nuestra reputación. 